\title{
Korean Society of Nephrology 2021 Clinical Practice Guideline for Optimal Hemodialysis Treatment
}

\author{
Ji Yong Jung ${ }^{1}$, Kyung Don Yoo ${ }^{2}$, Eunjeong Kang ${ }^{3}$, Hee Gyung Kang ${ }^{4}$, Su Hyun Kim ${ }^{5}$, Hyoungnae Kim ${ }^{6}$, \\ Hyo Jin Kim ${ }^{7}$, Tae-Jin Park ${ }^{8}$, Sang Heon Suh ${ }^{9}$, Jong Cheol Jeong ${ }^{10}$, Ji-Young Choi ${ }^{11}$, Young-Hwan Hwang ${ }^{12}$, \\ Miyoung $\mathrm{Choi}^{13}$, Yae Lim Kim ${ }^{14}$, Kook-Hwan $\mathrm{Oh}^{15}$, for the Korean Society of Nephrology Clinical Practice \\ Guideline Work Group
}

\footnotetext{
${ }^{1}$ Division of Nephrology, Department of Internal Medicine, Gachon University Gil Medical Center, Gachon University College of Medicine, Incheon, Republic of Korea

${ }^{2}$ Division of Nephrology, Department of Internal Medicine, Ulsan University Hospital, University of Ulsan College of Medicine, Ulsan, Republic of Korea

${ }^{3}$ Division of Nephrology, Department of Internal Medicine, Ewha Womans University Seoul Hospital, Ewha Womans College of Medicine, Seoul, Republic of Korea

${ }^{4}$ Division of Pediatric Nephrology, Department of Pediatrics, Seoul National University Children's Hospital, Seoul, Republic of Korea

${ }^{5}$ Division of Nephrology, Department of Internal Medicine, Chung-Ang University Hospital, Seoul, Republic of Korea

${ }^{6}$ Division of Nephrology, Department of Internal Medicine, Soonchunhyang University Seoul Hospital, Seoul, Republic of Korea

${ }^{7}$ Division of Nephrology, Department of Internal Medicine, Pusan National University Hospital, Busan, Republic of Korea

${ }^{8}$ Asan Jin Internal Medicine Clinic, Seoul, Republic of Korea

${ }^{9}$ Division of Nephrology, Department of Internal Medicine, Chonnam National University Hospital, Gwangju, Republic of Korea

${ }^{10}$ Division of Nephrology, Department of Internal Medicine, Seoul National University Bundang Hospital, Seongnam, Republic of Korea

${ }^{11}$ Division of Nephrology, Department of Internal Medicine, Kyungpook National University Chilgok Hospital, Daegu, Republic of Korea

${ }^{12}$ Truewords Dialysis Clinic, Incheon, Republic of Korea

${ }^{13}$ Division for Healthcare Technology Assessment Research, National Evidence-Based Healthcare Collaborating Agency, Seoul, Republic of Korea

${ }^{14}$ Department of Biostatistics, Korea University College of Medicine, Seoul, Republic of Korea

${ }^{15}$ Division of Nephrology, Department of Internal Medicine, Seoul National University Hospital, Seoul, Republic of Korea
}

Received: October 19, 2021; Accepted: October 19, 2021

Editor: Soo Wan Kim, Chonnam National University, Gwangju, Republic of Korea

Correspondence: Kook-Hwan Oh

Division of Nephrology, Department of Internal Medicine, Seoul National University Hospital, 101 Daehak-ro, Jongno-gu, Seoul 03080, Republic of Korea. E-mail: khoh@snu.ac.kr

ORCID: https://orcid.org/0000-0001-9525-2179 


\section{Contents}

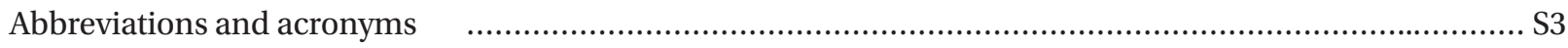

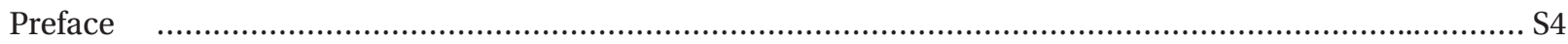

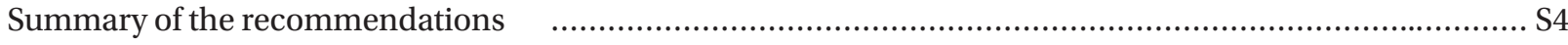

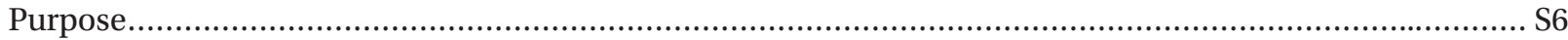

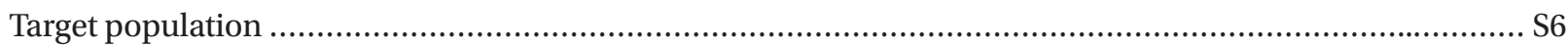

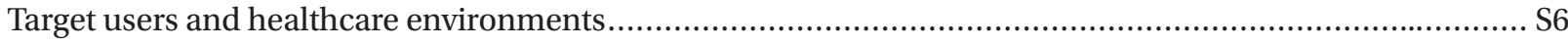

Composition of the clinical practice guideline development group .................................................... S6

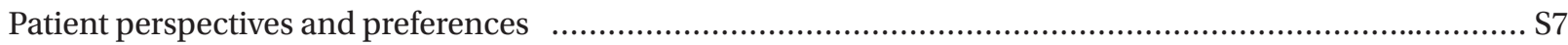

Methodology for clinical practice guideline development .......................................................... S7

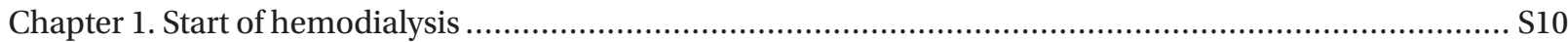

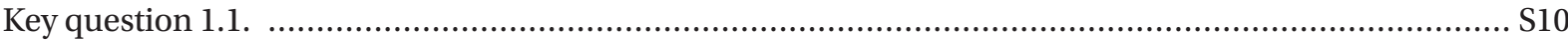

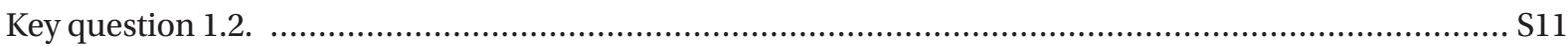

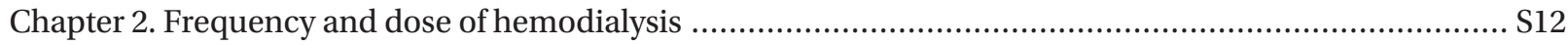

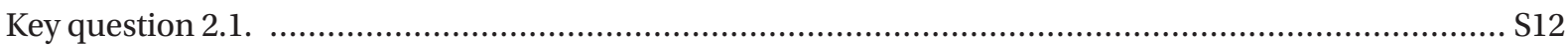

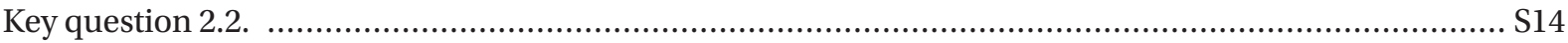

Chapter 3. Dialysis membrane and modality for hemodialysis ............................................... S15

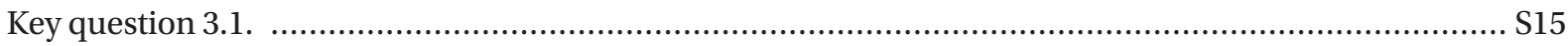

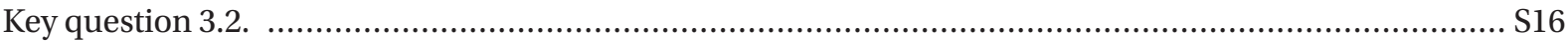

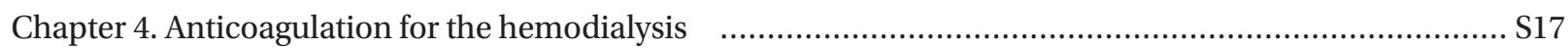

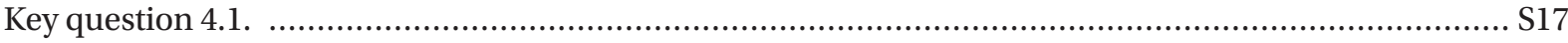

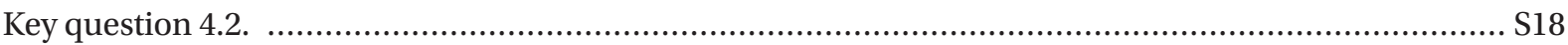

Chapter 5. Volume and fluid status in hemodialysis patients .................................................. S19

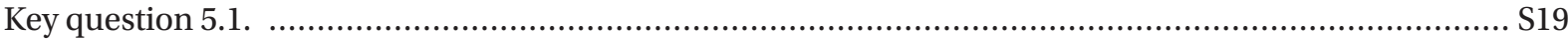

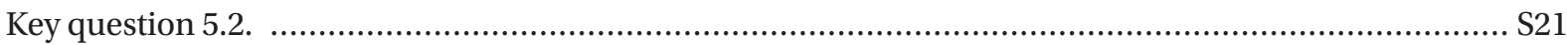

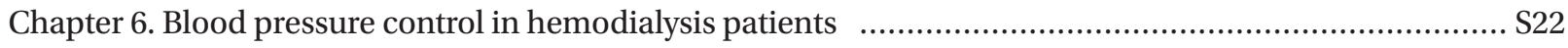

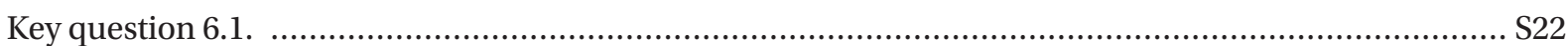

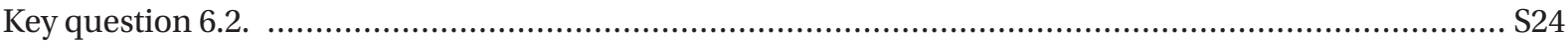

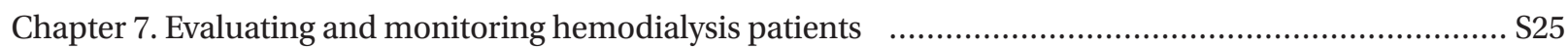

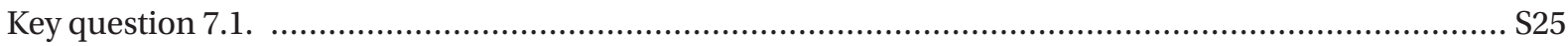

Chapter 8. Nonstandard settings of hemodialysis (elderly, children) ............................................ S26

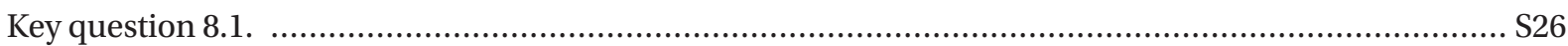

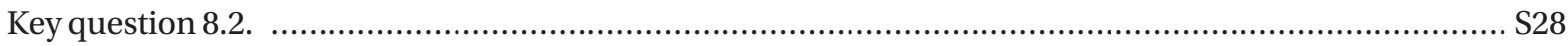

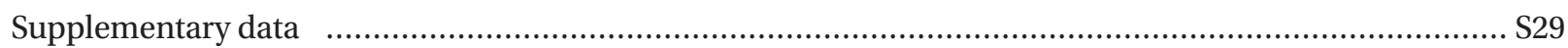

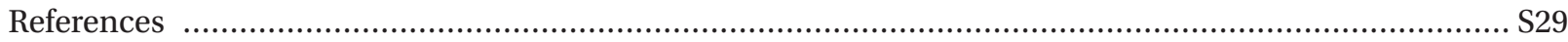




\section{Abbreviations and acronyms}

\begin{tabular}{|c|c|}
\hline AGREE & Appraisal of Guidelines for Research \& Evaluation Instrument \\
\hline AVF & Arteriovenous fistula \\
\hline AVG & Arteriovenous graft \\
\hline BUN & Blood urea nitrogen \\
\hline B2M & $\beta_{2}$ microglobulin \\
\hline $\mathrm{CBC}$ & Complete blood count \\
\hline $\mathrm{CI}$ & Confidence interval \\
\hline CKD & Chronic kidney disease \\
\hline CPG & Clinical practice guideline \\
\hline $\mathrm{Cr}$ & Creatinine \\
\hline $\mathrm{CV}$ & Cardiovascular \\
\hline DOPPS Dialysis & Outcomes and Practice Patterns Study \\
\hline eGFR & Estimated glomerular filtration rate \\
\hline ESHOL & Estudio de Supervivencia de Hemodiafiltración On-Line \\
\hline ESKD & End-stage kidney disease \\
\hline FRENCHIE & French Convective vs. Hemodialysis in the Elderly \\
\hline GFR & Glomerular filtration rate \\
\hline GRADE & Grading of Recommendations Assessment Development and Evaluation \\
\hline $\mathrm{Hb}$ & Hemoglobin \\
\hline HbAlC & Hemoglobin AlC \\
\hline HD & Hemodialysis \\
\hline $\mathrm{HDF}$ & Hemodiafiltration \\
\hline HEMO & Hemodialysis Study \\
\hline $\mathrm{HR}$ & Hazard ratio \\
\hline IDEAL & Initiating Dialysis Early and Late \\
\hline IDWG & Interdialytic weight gain \\
\hline KDIGO & Kidney Disease: Improving Global Outcomes \\
\hline KDOQI & Kidney Disease Outcomes Quality Initiative \\
\hline KSN & Korean Society of Nephrology \\
\hline LMWH & Low-molecular-weight heparin \\
\hline MD & Mean difference \\
\hline MHD & Maintenance hemodialysis \\
\hline MPO & Membrane Permeability Outcome \\
\hline OL-HDF & Online Hemodiafiltration \\
\hline OR & Odds ratio \\
\hline PICO & Population, Intervention, Comparator, and Outcome \\
\hline PTH & Parathyroid hormone \\
\hline RCT & Randomized controlled trial \\
\hline $\mathrm{RR}$ & Relative risk \\
\hline UFH & Unfractionated heparin \\
\hline URR & Urea reduction ratio \\
\hline
\end{tabular}




\section{Preface}

During the past 60 years, advances in hemodialysis (HD) technology and the application of medical insurance have allowed dialysis treatment to become widespread, enabling many patients with end-stage kidney disease (ESKD) to prolong their lives, and many changes have occurred in the treatment of dialysis patients. Therefore, various clinical practice guidelines (CPGs) for starting and maintaining HD have been published internationally. However, the clinical field, current HD technology, and target patients described in previously published CPGs are bound to change. In addition, the clinical evidence for HD has been continuously reinforced in follow-up studies after the publication of previous CPGs, creating demand for reevaluation of the related CPGs. In response to that demand, the Korean Society of Nephrology (KSN) established a CPG Committee and a Work Group, and proceeded with the entire process of planning, developing, reviewing, and disseminating appropriate HD treatment guidelines in accordance with international standards. We trust that this CPG will serve as optimal guidance and reference material for the treatment of domestic HD patients and in that way improve the health and quality of life of HD patients.

\section{Summary of the recommendations}

Table 1. GRADE (Grading of Recommendations Assessment Development and Evaluation) quality levels of evidence and meaning

\begin{tabular}{ll}
\hline Quality level & \multicolumn{1}{c}{ Definition } \\
\hline High & We are confident that the estimate of the effect is close to the actual effect. \\
Moderate & The estimates of the effect appear to be close to the actual effect, but it can vary considerably. \\
Low & The confidence in the estimate of the effect is limited. The actual effect could differ significantly from the estimate of the effect. \\
Very low & There is little confidence in the estimate of the effect. The actual effect will differ significantly from the estimate of the effect. \\
\hline
\end{tabular}

Table 2. GRADE strength of recommendation and meaning

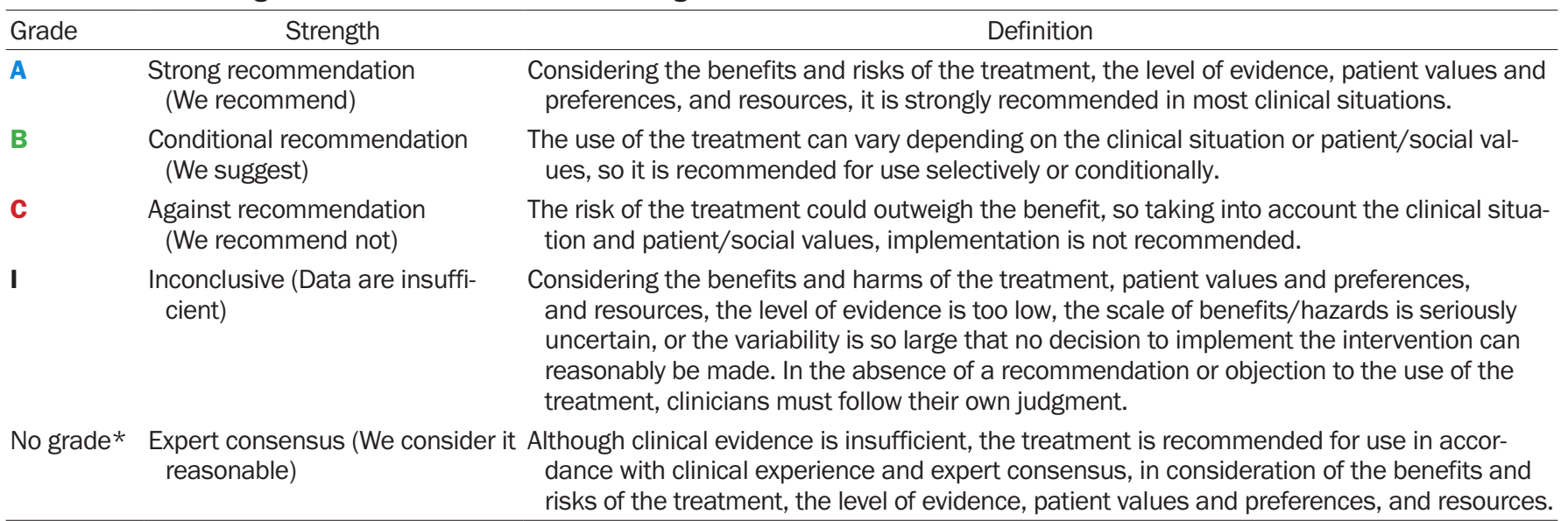

Each statement is shown as a combination of the strength of the recommendation and level of evidence.

* In the case of a consensus statement based on expert opinion, the recommendation grade and level of evidence are not indicated.

Table 3. Summary of the recommendations

\begin{tabular}{llc}
\hline Topic & \multicolumn{1}{c}{ Recommendations } & Strength \\
\hline 1. Start of HD & $\begin{array}{l}\text { 1.1. We recommend that whether and when to start HD be decided through a careful } \\
\text { discussion between the patient and the healthcare provider about the benefits/ } \\
\text { harms of the treatment and the patient's values and preferences about HD initiation } \\
\text { because an early start of HD, as determined by the GFR, in patients with CKD stage } \\
\text { G5 does not produce any differences in clinical outcomes from a late start. }\end{array}$ \\
\hline
\end{tabular}


Table 3. Continued

\begin{tabular}{|c|c|}
\hline Topic & Recommendations \\
\hline & $\begin{array}{l}\text { 1.2.1. We recommend the preparation of an arteriovenous access prior to HD initiation } \\
\text { to avoid central venous catheter insertion. }\end{array}$ \\
\hline & $\begin{array}{l}\text { 1.2.2. We consider it reasonable that the timing of an arteriovenous access } \\
\text { preparation be individualized according to patient comorbidities and GFR decline. }\end{array}$ \\
\hline \multirow[t]{2}{*}{$\begin{array}{l}\text { 2. Frequency and dose } \\
\text { of } \mathrm{HD}\end{array}$} & $\begin{array}{l}\text { 2.1. We recommend maintaining a dialysis at a frequency of at least three sessions } \\
\text { per week and for } 4 \text { hours or more for patients with minimal residual renal function. }\end{array}$ \\
\hline & $\begin{array}{l}\text { 2.2. We recommend a target dose of } 1.4 \text { single-pool Kt/ } \mathrm{V} \text { for patients receiving } \\
\text { thrice-weekly HD. }\end{array}$ \\
\hline \multirow[t]{3}{*}{$\begin{array}{l}\text { 3. Dialysis membrane and } \\
\text { modality for HD }\end{array}$} & $\begin{array}{l}\text { 3.1. We recommend the use of high-flux dialysis membranes in adult HD patients. } \\
\text { However, the cost and availability of high-flux membrane need to be considered. }\end{array}$ \\
\hline & $\begin{array}{l}\text { 3.2.1. There was no difference in all-cause mortality, cardiovascular mortality, hospital- } \\
\text { ization rate and quality of life in online hemodiafiltration (HDF) compared with high- } \\
\text { flux HD. }\end{array}$ \\
\hline & $\begin{array}{l}\text { 3.2.2. We consider it reasonable to apply high-volume online HDF after considering the } \\
\text { cost-effectiveness in some cases. }\end{array}$ \\
\hline
\end{tabular}

4. Anticoagulation for the HD 4.1. We recommend using unfractionated heparin (UFH) as the standard for systemic anticoagulation in HD patients without an increased bleeding risk because no differences could be found in the bleeding outcomes or circuit thrombosis between UFH and low-molecular-weight heparin (LMWH).

4.2.1. We recommend not to use heparin for anticoagulation in HD patients with a high risk of bleeding.

4.2.2. We suggest using nafamostat mesylate, instead of heparin, for anticoagulation in HD patients with a high risk of bleeding.

5. Volume and fluid status in HD patients

6. Blood pressure control in HD patients
5.1.1. We suggest that the weight-gain ratio between dialysis sessions not exceed $4 \%$ compared with the dry weight before dialysis.

5.1.2. We consider it reasonable that patients whose body weight before dialysis exceeds $4 \%$ compared with the dry weight require an assessment of excess body fluids, dietary compliance, and nutritional status along with the provision of dietary education.

5.2. We suggest that the change of conventional dialysate sodium (138-140 mEq/L) to low dialysate sodium $(<138 \mathrm{mEq} / \mathrm{L})$ to maintain adequate volume status. Attention should be paid to the possibility of developing intradialytic hypotension and muscle cramps while using low sodium dialysis.

6.1.1. There is insufficient evidence to assign optimal blood pressure target for HD patients.

6.1.2. We consider it reasonable that antihypertensive medications should be prescribed for hypertensive HD patients considering multi-factors.

6.2. We suggest lowering the dialysate temperature to reduce intradialytic hypotension.

7. Evaluating and monitoring 7.1.1. We consider it reasonable to test dialysis adequacy at least every 3 months in HD patients patients on maintenance HD.

7.1.2. We consider it reasonable to perform CBC tests, liver function tests, and routine chemistry tests at least monthly in patients on maintenance HD.

7.1.3. We consider it reasonable to test iron status, $\mathrm{PTH}$, and $\mathrm{HbA1C}$ (in diabetic patients) and perform a chest radiograph at least every 3 months in patients on maintenance HD.

7.1.4. We consider it reasonable to test hepatitis viral markers and perform electrocardiography at least every 6 months in patients on maintenance HD.

8. Nonstandard settings for HD (elderly, children)
8.1.1. We suggest that preparation for appropriate renal replacement therapy be considered for elderly patients who progress to ESKD.

8.1.2. We consider it reasonable that in elderly patients with ESKD, the optimal treatment should find an individualized balance between appropriate renal replacement therapy and conservative treatment.

8.2.1. For HD of children younger than 5 years old, we consider it reasonable that the minimal nurse-to-patient ratio be 1:1.

8.2.2. For $\mathrm{HD}$ of older children, we consider it reasonable that the minimal nurse-topatient ratio be 1:2.

Strength Quality

A Low

Expert consensus
A Moderate
A Moderate
A High
B Moderate

Expert consensus
A Low
C Low
B Low

B Moderate

Expert consensus

B Moderate

I Very low

Expert consensus

B Moderate

Expert consensus

Expert consensus

Expert consensus

Expert consensus

B Moderate

Expert consensus

Expert consensus

Expert consensus 


\section{Purpose}

HD treatment is a special field that requires more than a certain period of patient care experience. Even when standardized treatment is provided in an HD unit, clinicians have to make decisions on their own, taking into account all aspects of an individual patient's situation. This CPG is based on clear evidence for the benefits of preparation, initiation, and maintenance of HD therapy and has been produced with the participation of representative experts from nephrology-related societies using a methodology suitable for establishing a CPG. It is intended to help clinicians participating in HD to make safer and more effective clinical decisions by providing them with information in a user-friendly manner. It is also intended to be used as an educational resource for residents, fellowship holders, and doctors in charge of education and training and seeks to find areas with questions that remain to be answered through additional research. In the end, the ultimate goal for this CPG is that it will be widely adopted as a standard for appropriate HD treatment in patients with ESKD and thereby contribute to prolonging the lives of dialysis patients, improving their quality of life, and improving public health care by ensuring that limited health care resources are used efficiently.

\section{Target population}

This CPG applies to clinicians, patients, and subjects related to HD in the Republic of Korea, including all patients who visit medical institutions for the purpose of receiving HD. It also provides specific and comprehensive information about when to start HD and how to prepare, test, and follow up with inpatients who have ESKD. Content about conservative treatments, such as nutritional imbalances and psychological support relevant to ESKD and dialysis, has been excluded. Information about starting and stopping temporary HD to treat acute kidney injury has also been excluded. Therefore, clinicians treating patients with ESKD who are considering HD and those currently undergoing HD therapy are the main targets of this CPG.

\section{Target users and healthcare environments}

This CPG includes clinical information for all medical staff and stakeholders, including specialists, residents, fellow- ship, and nurses, at primary, secondary, and tertiary medical institutions that conduct HD treatment in the Republic of Korea. In addition, it provides specific and practical information for residents, fellowship holders, nurses, and the educators who lead them. In the process of developing this CPG, we reviewed whether the underlying research results and their application in the Korean medical environment were well balanced through consultations with various experts. This CPG provides concise and accurate information so that medical staff caring for HD patients can offer evidence-based treatment in a variety of medical environments, from primary medical institutions to certified tertiary hospitals.

\section{Composition of the clinical practice guideline development group}

In consideration of expertise, representativeness, and continuity, the Work Group was established in consultation with the KSN Board of Directors. The Work Group was organized by the chairperson of the CPG Committee consisting of nephrologists and pediatric nephrologists recommended by KSN and its affiliated research groups (Supplement 1). The Work Group has 15 members (experts in the field of CPG development methodology and in the field of adult and pediatric nephrology, including two dialysis primary care physicians, who are engaged in HD work at various medical institutions) to ensure the diversity of related expert groups. One methodology expert and one working member collaborated to search the literature, establish a methodology for systematic literature research, and establish the development of this CPG.

All members of the Work Group completed several workshop trainings about stage-by-stage development methods and pilot research cases from methodology experts who participated in the development of this CPG to maximize the efficiency of the CPG development plan. In addition, some members of the Work Group participated in the Korean Internal Medicine Standards Guidelines Committee Workshop (September 12, 2020) and received additional training during the treatment CPG development process.

In the Work Group, the key questions were divided into eight topics and 15 questions, and one sub-chairperson was selected for each topic. Operational meetings in which all members discussed the contents of each division oc- 
curred once a month. In that way, the members of the Work Group collaborated to decide which subjects should be covered in the guidelines, searched the literature, conducted critical reviews and meta-analyses, and determined evidence levels. Draft recommendations for individual topics prepared by each member were reviewed by the Work Group, and the final recommendations and recommendation grades were determined with the consent of all members. Major development stages (selection of key questions, search for and selection of evidence, preparation of evidence tables, quality evaluation, drafting of recommendations, etc.) were developed with support from methodology experts, who conducted the final review.

\section{Patient perspectives and preferences}

Each recommendation was reviewed by the Work Group, who discussed problems that might arise while applying the recommendations to patients in the clinic. The text of the CPG describes patient values and preferences, obstacles, and facilitating factors. By presenting a plan to overcome the identified problems, efforts were made to balance the use of other resources with HD treatment in the Republic of Korea.

\section{Methodology for clinical practice guideline development}

CPG development was conducted in three stages: planning, development, and review and dissemination. The main processes related to the development of the actual recommendations were 1) selection of key questions, 2) evidence search, 3) evaluation and synthesis of evidence, 4) determination of the recommendation grade and level of evidence, 5) preparation of recommendations, and 6) coming to agreement.

\section{1) Declaration and management of conflicts of interest}

All members of the Work Group provided a conflict-of-interest disclosure before participating in the development of the CPG and upon completion of the CPG to determine whether anyone had a financial or nonfinancial conflict of interest, and each member's conflict-of-interest report and management evaluation are shown in Supplement 2. When members reported corporate research sponsorships or consulting, their detailed report contents were confirmed in a review by the Work Group, which determined the amount of money and whether the content of a recommendation might have been affected. If the amount exceeded the standard and might have affected the content of a recommendation, the opinion of that member was excluded when determining the direction and strength of that recommendation. This principle was applied from the beginning to the end of development.

\section{2) Selection of key questions}

The final recommendations were derived from the key questions, which were chosen by reviewing existing CPGs, selecting detailed topics and clinical problems, reviewing the evidence for each topic, and selecting the final eight detailed topics. Many clinical and methodology experts participated in selecting the core questions and reviewing the recommendations, and their opinions are reflected in the final draft as much as possible. In this process, a survey of nephrology experts, the main intended users of these guidelines, was conducted, the process for developing the guidelines was announced at an academic conference, and the opinions of KSN members were collected. Key questions were written in consideration of the PICO (Population, Intervention, Comparator, and Outcome) factors and are presented in PICO format. Thus, a sentence-type key question was written, and the development possibility was reviewed and finally confirmed (Supplement 3 ).

\section{3) Determination of the development method}

This CPG is mostly an adaptation of existing domestic and overseas guidelines, and the latest research results have been added. In cases in which no recommendations were found in the existing guidelines, a de novo method was selectively reviewed. The adaptation development method used existing CPGs as the most important source of evidence, though some systematic changes were applied to suit the medical situation in the Republic of Korea.

\section{4) Search and selection of evidence}

Our literature search combed major domestic and foreign literature search databases, Ovid-Medline, Ovid-Embase, Cochrane Library, KoreaMed, etc., and focused on the keywords in each key question selected by the Work Group. The reviewers also conducted additional manual searches. 
The following combinations of index words related to this CPG were searched: (hemodialysis[ti] OR haemodialysis[ti] OR dialysis[ti]) AND guideline[ti] NOT peritoneal[ti] AND "2011/01/01"[PDAT]: "2020/06/30" [PDAT]). After excluding duplicates, a total of 189 medical guidelines were extracted as a result of our search. The literature selection criteria were prepared according to the key questions, and during the first and second selection/exclusion processes, each document was independently reviewed by two persons to increase objectivity. For the first screening, the titles and abstracts were reviewed, and for the second screening, the original text of all documents selected in the first screening was reviewed. In cases of exclusion, the reason for exclusion was described. If the reviewers disagreed during the two-stage screening process, consensus was reached through a specific process, and in that way the final 14 documents were confirmed (Supplement 4).

The literature search considered studies and CPGs published before October 2020. Papers published since then have been reinforced with narratives as much as possible. In the case of new direct methods (three key questions in the "anticoagulant therapy" and "special situations" sections), an additional search of the domestic and international CPG database (Guideline International Network, Korean Clinical Practice Guideline Information Center) was made. To increase the sensitivity of the search, similar key questions were linked by using only the $[\mathrm{P}]$ and $[\mathrm{I}]$ of PICO. Our search strategy was systematically constructed with the help of a methodology expert, and final recommendations were made by performing a search of domestic and foreign databases. The search formula for the literature in each area is described in Supplements 4 and 5.

\section{5) Evidence quality evaluation}

After reviewing the original text of each study, the quality of the CPGs selected was evaluated by two persons using the AGREE (Appraisal of Guidelines for Research \& Evaluation Instrument) 2 tool. The K-AGREE evaluation form developed by the Korean Medical Association was used to reduce variation among evaluators. The AGREE scores ensure the reproducibility and clarity of the evaluation result by providing a process that can be corrected (e.g., if there is a difference of 4 points or more between reviewers). The evaluation result was derived using the scoring formula for each area. Treatment guidelines with a developmental rigor of 50 points or more were selected for establishing recommendations and evidence.

\section{6) Preparation of recommendation comparison table and evaluation of acceptance/applicability}

After we reviewed the selected CPGs, we made a comparison table of recommendations for each key question and evaluated their domestic acceptance and applicability. The contents of these discussions are reflected in the recommendations, and a comparison table of the recommendations and a table of acceptance and applicability were prepared for each key question.

\section{7) Preparation of evidence table}

The documents supporting the recommendations related to the key questions of this CPG were extracted from the selected CPGs and arranged in the form of an evidence table. The evidence table was then completed by adding the latest literature found through additional literature searches. All documents included in the evidence table were compiled in the "Summary evidence tables" for the recommendations for each key question (Supplement 6).

\section{8) Bias risk assessment}

A risk of bias assessment appropriate to each study design was conducted and collected into a risk of bias graph. The risk of bias assessments used validated checklists recommended by the Cochrane Collaboration: the Cochrane Risk of Bias tool 2.0 for randomized controlled trials (RCTs), Risk of Bias for non-randomized studies, and the Measurement Tool for Assessment of Multiple Systematic Reviews for Systematic Reviews (Supplement 7). Data were compiled centrally by the Work Group.

\section{9) Synthesis of evidence \\ - Data extraction}

Documents selected from the evidence table of existing CPGs and additionally searched documents were classified by study design, and needed topics were selected from the list of available data to extract the relevant content. Data extraction was performed according to a predetermined data extraction format (data values reported in forest plots, tables, etc., were reviewed and accepted). In comparisons between two intervention methods, a data extraction format that could evaluate the comparability was used. One 
working member extracted the data and another working member reviewed it.

\section{- Data analysis and synthesis}

After the final evidence table, including the evidence from existing CPGs and the additional searched literature, was completed, a meta-analysis was performed when quantitative synthesis of the extracted data was possible, and qualitative descriptions were made if no synthesis was possible (Supplements 8 and 9).

When a meta-analysis was possible, the heterogeneity of the data was evaluated. When the heterogeneity was judged to be high, a random-effect model was applied, and a subgroup analysis was performed to search for the cause of the heterogeneity. Publication bias was explored by applying Egger's test and the Trim-and-Fill method when more than 10 studies were included in the synthesis. Cochrane's Review Manager 5.4 was used as the meta-analysis statistics program.

\section{0) Arrangement of evidence level and recommendation grade}

The levels of evidence were evaluated using the GRADE methodology. The importance of each result was evaluated first, and then the level of evidence for each result was determined as high, moderate, low, or very low. The meaning of the evidence levels is shown in Table 1.

The recommendation grades have four levels: strong recommendation, conditional recommendation, against recommendation, and inconclusive (Table 2). As factors in making recommendations, we considered the level of evidence, benefits and harms, clinical applicability, resources and costs, and patient values and preferences.

The key questions for which recommendations could not be adapted or developed directly due to poor existing research are answered through expert consensus.

\section{1) Recommendation formulation}

In the process of formulating the recommendations to improve their clinical implementation, the working members reviewed their feasibility and made suggestions about obstacles, facilitating factors, and solutions. Then, draft recommendations were vetted through discussion. After drafting, each recommendation was revised through a review process via e-mail and a wired meeting with experts in the relevant field. Otherwise, review was conducted informally by the Work Group, and all members agreed at a plenary meeting. This process did not use formal consensus methods such as voting, but instead proceeded through indepth discussions. After that, the Work Group wrote and confirmed the final recommendation levels to reflect the review members' opinions. In the end, 15 recommendations were developed within the final eight topics (Table 3).

\section{2) Independent external review}

To collect consultation and external review opinions before publication of the developed CPG, an external advisory committee composed of clinical experts and methodology experts intended to be end-users of the recommended practice guidelines was formed from the research groups within the KSN, the Korean Society of Dialysis Therapy, the Korean Society of Dialysis Access, and the Korean Society of Diagnostic and Interventional Nephrology. This advisory committee did not prepare recommendations to be included in the CPG but served as an external reviewer who consulted at the stage of consensus on the derived recommendations. For the external review, an expert questionnaire survey was conducted to investigate the degree of consent to the recommendations for each key question. The advisory committee (including one methodology expert) completed the survey, which used a scale from 1 point (strong disagreement) to 5 points (strong agreement) to indicate the degree of consent to each recommendation. The questionnaire allowed the key question, draft recommendation, recommendation grade, and evidence level to be viewed at a glance. It also asked about the necessity and appropriateness of the guidelines, the methodological strictness of the process used to develop the guidelines, the rationality of the recommendations, the degree of agreement with and usefulness of the overall CPG, and whether respondents had revision suggestions for individual recommendations (Supplement 10). In addition, a separate document and protocol summarizing the step-by-step development process was provided as a reference for respondents. The draft file was circulated by e-mail to the advisory committee and each society to obtain opinions, and then the Work Group members, advisors, recommended persons from related societies, and interested experts and methodology experts gathered to reflect on the stakeholder participation, external review, and opinions of the implementation plans. In 
that meeting, feedback was obtained, and the revised opinions were reflected in the contents of the treatment guidelines (Supplement 11). Since then, dozens of e-mails and phone calls have been made to the working-level members and members of each society to collect and revise opinions about the review and processing contents (reflected or not and why), and this CPG has obtained certification by the Korean Association of Internal Medicine.

\section{3) Update plan for this clinical practice guideline}

The primary users of this evidence-based CPG for appropriate HD treatment are those who care for HD patients. We will continue to derive necessary key questions, generate recommendations based on evidence, and update existing recommendations as evidence changes.

Key questions for new evidence-based CPGs will be developed by considering the opinions of patients, related workers, and clinical experts. It is necessary to first seek opinions from medical consumers and clinicians in the field about the key questions that need to be developed and then introduce a method for developing an HD treatment CPG based on them. Because CPGs produced using the acceptance and adaptation method are mainly based on research conducted abroad, it is necessary to develop appropriate recommendations fitted to the domestic situation. Therefore, the results of domestic research are much needed. To accumulate data, the Work Group will promote domestic research to related academic societies and seek cooperation. It was decided to consider updating these developed recommendations by reviewing new evidence every 3 to 5 years.

In terms of national policies such as insurance benefits and HD adequacy evaluation variables and standards, it is possible to predict use of this appropriate, evidence-based, HD treatment CPG as a policy reference. In addition, it will be used as a practical educational tool for clinicians who lack in-depth expertise or experience in HD and to develop data for patients, who have the right to self-determination and discussion in decisions related to HD.

\section{Chapter 1. Start of hemodialysis}

\section{Key question 1.1.}

In adult CKD patients who require $\mathrm{HD}$, does the early start of
HD improve outcomes in terms of patient survival, cost-effectiveness, or complications, compared with a late start?

\section{Recommendation}

We recommend that whether and when to start HD be decided through a careful discussion between the patient and the healthcare provider about the benefits/harms of the treatment and the patient's values and preferences about HD initiation because an early start of HD, as determined by the GFR, in patients with CKD stage G5 does not produce any differences in clinical outcomes from a late start.

Recommendation grade: strong recommendation (A)

Level of evidence: moderate

\section{- Summary of evidence}

The decision to start dialysis is influenced by a variety of factors, including signs and symptoms of uremia, biochemical tests, and the GFR. The exact timing of dialysis initiation will likely affect the cost of dialysis services and clinical outcomes, so when deciding to start dialysis, the risks, degree of improvement in symptoms and functioning, quality of life, and other medical expenses should be addressed.

No studies have investigated the start of dialysis based on patient symptoms. A randomized study (IDEAL; Initiating Dialysis Early and Late) compared the clinical outcomes of relatively early and late starting groups based on the GFR [1], and the results of three sub-analyses of that randomized study were published [2-4].

In the comparison of the early-start group (GFR of 10-14 $\mathrm{mL} / \mathrm{minute} / 1.73 \mathrm{~m}^{2}$ ) and the late-start group (GFR of 5-7 $\mathrm{mL} / \mathrm{minute} / 1.73 \mathrm{~m}^{2}$ ), no difference was found between the two groups in major clinical outcomes such as mortality, quality of life, hospitalization, and infection [1].

In addition, we synthesized evidence through a meta-analysis of various retrospective studies, including domestic research results [5-14]. We also found neither benefit nor harm from starting HD relatively early or late. However, because the heterogeneity among the retrospective studies used in our synthesis of evidence was very high and there was no consistency in their quality of evaluation, our level of evidence for this recommendation is moderate.

(Supplement 3 | Review questions-PICO format-Key question 1.1.)

(Supplement 4 | Search strategies-Key question 1.1.) 
(Supplement 5 | Study selection flow diagrams-Key question 1.1.)

(Supplement 6| Summary evidence tables-Key question 1.1.) (Supplement 7|Bias risk assessment-Key question 1.1.)

(Supplement 8 | Clinical evidence profiles (GRADE tables)Key question 1.1.)

(Supplement 9|Forest plots-Key question 1.1.)

\section{- Recommended considerations}

1) Benefits and harms

Overall, starting dialysis relatively early appears to have no benefit or harm compared with starting dialysis late. However, in the IDEAL study, $76 \%$ of the patients in the latestart group started with a GFR higher than $7 \mathrm{~mL} / \mathrm{min} / 1.73$ $\mathrm{m}^{2}$, so there might have been no significant difference in the actual GFR at the start of dialysis between the two groups. Therefore, we have no information about patients who do not start dialysis until they have a very low GFR.

\section{2) Patient values and preferences}

In some cases, patients might be able to decide when to start dialysis because they have sufficient awareness of possible symptoms and signs from delayed dialysis, but more often, dialysis is difficult to accept, and patients tend to delay starting until major symptoms develop. Although little evidence suggests that early dialysis initiation has distinct advantages over delayed dialysis initiation, waiting too long to prepare for initiation can worsen clinical outcomes. Therefore, the optimal timing for initiating dialysis depends on a variety of complex data, taking into account the needs of the patient, their family, and the medical staff in a balanced manner.

\section{3) Obstacles, facilitating factors, and measures}

If a patient who imminently requires dialysis wants to delay initiation, the commencement of dialysis should be decided by considering the desires of the patient and their family alongside the complications of delayed dialysis and the benefits of dialysis initiation. Symptoms of uremia vary and can include itching, nausea, fatigue, depression, and anxiety. In severe cases, it can be accompanied by pericarditis and seizures. The degree to which uremia can affect daily life varies widely, and preventing the complications of delayed dialysis is important. Therefore, even in asymptomatic patients, when the GFR reaches $5-7 \mathrm{~mL} / \mathrm{min} / 1.73 \mathrm{~m}^{2}$, the start of dialysis can be considered.

\section{4) Resources}

The IDEAL studies suggested that the delayed-start strategy for dialysis is more cost-effective than the early-start strategy, mainly because the period of exposure to dialysis is longer with the early-start strategy, which increases the cost. Since the publication of the IDEAL results, many countries have begun to strategically avoid early dialysis initiation in asymptomatic patients.

\section{Key question 1.2.}

In adult CKD stage G5 patients, does the preparation of vascular access prior to the initiation of dialysis improve patient survival, compared with non-preparation of vascular access?

\section{Recommendation}

1. We recommend the preparation of an arteriovenous access prior to $\mathrm{HD}$ initiation to avoid central venous catheter insertion.

Recommendation grade: strong recommendation (A)

Level of evidence: low

2. We consider it reasonable that the timing of an arteriovenous access preparation be individualized according to patient comorbidities and GFR decline.

Recommendation grade: expert consensus

\section{- Summary of evidence}

The purpose of preparing an arteriovenous access for HD, such as an arteriovenous fistula (AVF) or arteriovenous graft (AVG), is to prevent unnecessary central venous catheter insertion at the time of dialysis initiation. Central venous catheter insertion is associated with catheter-related infections, central vein stenosis, pneumothorax, and additional unnecessary medical expenses.

Most studies about preparing arteriovenous access investigated the clinical outcomes from different types of arteriovenous access and different timings of preparation. No RCT has been done, and most research consisted of observational studies of cohort data. Low mortality and low hospitalization rates were reported in the native AVF group [15-18]; however, selection bias cannot be completely excluded due to the nature of observational studies.

A survival benefit for patients with AVF formation was 
reported; however, preparation of AVF was also associated with maturation failure [17]. Preparation of AVF and AVG was reported to have a trade-off relationship in elderly patients. AVG was superior for maturation, which led to shorter duration of central venous catheter placement and fewer interventions for delayed vascular access maturation. However, AVG had more cases of vascular access abandonment and secondary operations after maturation. Compared with AVG, AVF showed longer vascular access survival and fewer secondary interventions after maturation.

Although we found no direct evidence for the exact timing of referral for arteriovenous access preparation, the recent Kidney Disease Outcomes Quality Initiative (KDOQI) stated that, based on expert opinion, referral for dialysis access assessment and subsequent creation should occur when estimated glomerular filtration rate (eGFR) is 15-20 $\mathrm{mL} / \mathrm{minute} / 1.73 \mathrm{~m}^{2}$. They also stated that, based on a well-designed Monte Carlo simulation model, earlier referral should occur in patients with unstable or rapid rates of eGFR decline (>10 mL/minute/year) [19,20].

(Supplement 3 | Review questions-PICO format-Key question 1.2.)

(Supplement 4| Search strategies-Key question 1.2.)

(Supplement 5 | Study selection flow diagrams-Key question 1.2.)

(Supplement 6 | Summary evidence tables-Key question 1.2.) (Supplement 7 | Bias risk assessment-Key question 1.2.)

\section{- Recommended considerations}

1) Benefits and harms

Preparing for arteriovenous access is beneficial to prevent complications related to the insertion of a central venous catheter, such as pneumothorax, catheter-related infections, and central vein stenosis. In addition, preparing an arteriovenous access can save the medical costs associated with catheter insertion. Although whether the reported survival benefits of arteriovenous access preparation are caused directly by reduced catheter-related infections should be investigated in further studies, a recent study reported that mortality after sepsis was higher in the AVG group than the AVF group [21]. A potential harm of preparing an arteriovenous access is unnecessary creation, defined as an AVF failure or patient death during the predialysis period, and that risk is elevated in elderly patients and female patients [22].

\section{2) Patient values and preferences}

When discussing the preparation of an arteriovenous access, patient values and preferences should be respected. The same is true for the placement of a central venous catheter because central vein stenosis and catheter-related infections are not deterministic. However, probabilistic guidance should reflect the risk factors of catheter-related complications. For instance, the high risk of catheter-related infections among diabetic patients should be considered when deciding about arteriovenous access preparation.

\section{3) Obstacles, facilitating factors, and measures}

A patient's desire to postpone initiation of dialysis could be an obstacle to the preparation of an arteriovenous access. Cosmetic concerns might exist. To overcome such hesitations, the benefits and potential risks of delayed dialysis initiation and arteriovenous access creation should be explained to patients, and the benefit-to-risk ratio should be understood. In addition, other renal replacement therapy options such as peritoneal dialysis or kidney transplantation should be explained, including the fact that those alternative options carry no need for arteriovenous access creation.

\section{4) Resources}

AVF formation was reported to be more cost-effective than AVG [23]. However, cost-effectiveness might depend on life expectancy and age. In patients older than 85 years, the cost-effectiveness of AVF diminished [24].

\section{Chapter 2. Frequency and dose of hemodialysis}

\section{Key question 2.1.}

What is the adequate frequency and duration of dialysis in patients undergoing HD?

\section{Recommendation}

We recommend maintaining a dialysis at a frequency of at least three sessions per week and for 4 hours or more for patients with minimal residual renal function.

Recommendation grade: strong recommendation (A)

Level of evidence: moderate 


\section{- Summary of evidence}

Since Scribner started intermittent MHD in patients with ESKD in 1960, a typical HD schedule has been three sessions for a total of 10-12 hours per week. In the Republic of Korea, the standard frequency and duration of dialysis are three sessions a week, typically for a total weekly time of 12 hours. Various frequencies of HD treatment can be used, such as daily home HD, which are not discussed in this guideline due to medical insurance issues in the Republic of Korea. It is not easy to define an appropriate number of sessions and duration of dialysis separately from the concepts of dialysis adequacy. Therefore, we searched for and summarized studies about the sessions and duration of dialysis.

Two randomized controlled studies of HD patients who received dialysis three times a week reported no significant differences in mortality (odds ratio [OR], 1.02; 95\% confidence interval [CI], 0.88-1.18; $\mathrm{p}=0.79$ ) or hospitalization rates (OR, 1.38; 95\% CI, 0.67-2.87; $\mathrm{p}=0.38$ ) between groups that received dialysis for more than 4 hours and less than 4 hours per session $[25,26]$. On the other hand, in four cohort studies with which a meta-analysis was possible, the mortality rate (OR, 1.34; 95\% CI, 1.15-1.55; $\mathrm{p}=0.0001$ ) was higher in the group that received dialysis for less than 4 hours than in the group that received dialysis for more than 4 hours per session [27-30]. Based on those findings, patients with minimal residual renal function should be maintained on dialysis at least three times a week, and duration should be 4 hours or more on at least one of those sessions [31]. Charra et al. [32] reported improved blood pressure control through long HD $(3 \times 8$ hours/ week $)$. Marshall et al. [33] found that the mortality rate was lower in the group receiving dialysis for more than 4.5 hours per session.

In addition, studies suggest that it is possible to try initiating twice-weekly HD in patients who retain significant residual kidney function. In our meta-analysis of three such studies, the mortality rate tended to increase in HD patients without residual renal function, so such a schedule should be attempted while sufficiently watching changes in the patients' residual renal function [34-36].

(Supplement 3 | Review questions-PICO format-Key question 2.1.)

(Supplement 4|Search strategies-Key question 2.1.)
(Supplement 5 | Study selection flow diagrams-Key question 2.1.)

(Supplement 6| Summary evidence tables-Key question 2.1.) (Supplement 7|Bias risk assessment-Key question 2.1.)

(Supplement 8 | Clinical evidence profiles (GRADE tables)— Key question 2.1.)

(Supplement 9|Forest plots-Key question 2.1.)

\section{- Recommended considerations}

\section{1) Benefits and harms}

In HD patients, dialysis three times a week, 4 hours per session, is considered the minimum requirement to extend patient lifespans and reduce cardiovascular (CV) mortality. It is difficult to increase the number of dialysis sessions or the dialysis time due to insurance standards in the Republic of Korea. In some patients with clinical symptoms of pulmonary edema or uremia (uremic pericarditis, etc.), an increase in the number of dialysis prescriptions can be considered. In dialysis patients without residual renal function, reducing the time or frequency of sessions can lead to life-threatening pulmonary edema and uremia.

\section{2) Patient values and preferences}

Patients often ask their doctors to reduce the number of dialysis sessions or the time per session. In particular, patients who want the prescribed dialysis time to be reduced little by little require education to maintain an adequate frequency and duration of dialysis. If a patient's expected survival time is less than 6 months, conservative treatment is necessary. If such patients request it, dialysis can be performed twice a week or for less than 4 hours per session $[37,38]$. In such cases, it is necessary to watch for the sudden onset of pulmonary edema or uremia symptoms.

\section{3) Obstacles, facilitating factors, and measures}

Some studies consider starting with dialysis twice a week in patients with initial residual renal function. Still, residual renal function can decrease rapidly in HD patients, so clinicians should pay sufficient attention to the residual renal function of their dialysis patients.

\section{4) Resources}

In dialysis patients, symptoms of sudden swelling and uremia can develop after the number and duration of dialysis sessions decreases. In such cases, the number of emergen- 
cy dialysis sessions and hospitalization rates can increase, which increases the cost. Therefore, it is important to try to keep to the frequency and duration of dialysis recommended in this guideline.

\section{Key question 2.2.}

In adult patients maintaining HD, does high-dose dialysis improve the survival rate compared with low-dose dialysis?

\section{Recommendation}

We recommend a target dose of 1.4 single-pool Kt/ $\mathrm{V}$ for patients receiving thrice-weekly HD.

Recommendation grade: strong recommendation (A)

Level of evidence: moderate

\section{- Summary of evidence}

The adequacy of HD has traditionally been measured by evaluating the clearance of small molecules such as urea. Since the Kt/V metric, which consists of dialyzer clearance $(\mathrm{K})$, dialysis time $(\mathrm{t})$, and volume of distribution (V), was presented, many observational studies have consistently reported that dialysis with increased $\mathrm{Kt} / \mathrm{V}$ was significantly associated with a survival benefit in patients on MHD [29,39-48].

The representative study for this issue is the HEMO (Hemodialysis) Study published in 2002 [49]. In that randomized clinical trial of 1,846 patients undergoing thrice-weekly HD, the high-dose group maintaining a mean single pool $\mathrm{Kt} / \mathrm{V}(\mathrm{spKt} / \mathrm{V})$ of 1.71 had no significant benefit in terms of morbidity or mortality compared with the standard group maintaining a mean spKt/V of 1.32 .

Therefore, because the aforementioned observational studies reported increased mortality rates under an inadequate dialysis dose, we recommend maintaining an appropriate dialysis time with a qualified dialysis system to obtain the recommended spKt/V 1.4. However, as the HEMO Study showed no improvement in morbidity or mortality rate with high-dose dialysis, increasing the dialysis dose beyond the recommended level is unnecessary.

The urea reduction ratio (URR) and equilibrated Kt/V (eKt/V) are other methods to assess dialysis adequacy. URR is simple and easy to calculate, but it inaccurately assesses dialysis adequacy because it does not take into account the volume of urea distribution. The eKt/V is lower than that of
spKt/V because it is calculated by considering the redistribution of urea after dialysis. In the HEMO Study, the mean $\mathrm{eKt} / \mathrm{V}$ in the standard group (mean spKt/V of 1.32) was 1.16. In general, the corresponding $\mathrm{eKt} / \mathrm{V}$ is 1.2 when the target dialysis dose in terms of spKt/V is 1.4.

(Supplement 3 | Review questions-PICO format-Key question 2.2.)

(Supplement 4 | Search strategies-Key question 2.2.)

(Supplement 5 | Study selection flow diagrams-Key question 2.2.)

(Supplement 6 | Summary evidence tables-Key question 2.2.)

(Supplement 7 | Bias risk assessment-Key question 2.2.) (Supplement 8 | Clinical evidence profiles (GRADE tables)-Key question 2.2.)

\section{- Recommended considerations}

\section{1) Benefits and harms}

The eKt/V is a method that considers the redistribution of urea. Therefore, eKt/V should be obtained by performing additional blood sampling 30 minutes after the end of the dialysis session or by calculating mathematically based on previously developed equations [50]. However, there is insufficient evidence that dialysis adequacy assessment using $\mathrm{eKt} / \mathrm{V}$ can provide additional benefits compared with using spKt/V.

\section{2) Patient values and preferences}

The assessment of HD adequacy does not reflect patients' values and preferences.

\section{3) Obstacles, facilitating factors, and measures}

Since the introduction of high-flux membranes, low dialyzer clearance has not been an obstacle to obtaining an adequate dialysis dose. However, spending more than 12 hours on dialysis over the course of three sessions a week still degrades the patient's quality of life, and a patient's demand to reduce dialysis time can be a barrier to maintaining dialysis adequacy. Thus, to obtain a sufficient dialysis dose, Kt/V should be measured regularly, and patients should be educated about the need to maintain dialysis adequacy. Considering that the within-patient coefficient of variation of spKt/V was about $10 \%$ in the HEMO Study, a minimum spKt/V of 1.2 must be achieved when target- 


\section{ing a spKt/V of 1.4.}

In addition, because most dialysis dose studies were conducted in patients undergoing dialysis three times a week, it is difficult to apply our recommendation to patients who undergo dialysis on different schedules. The weekly standardized Kt/V can be applied to patients with a dialysis schedule other than thrice-weekly [51]. Previous observational studies reported the relationship between weekly standardized Kt/V and mortality in those patients $[47,52,53]$, but high-level evidence is still lacking. Therefore, further studies are needed to validate dialysis adequacy assessments for patients undergoing dialysis on a schedule other than three times a week.

\section{4) Resources}

Inadequate dialysis can lead to unnecessary consumption of medical resources due to additional hospitalizations. In addition, because high-dose dialysis was not associated with a survival benefit in the HEMO Study, the implementation of a dialysis dose above the recommended level can also be an unnecessary use of dialysis resources.

\section{Chapter 3. Dialysis membrane and modality for hemodialysis}

\section{Key question 3.1.}

In adult patients receiving $\mathrm{HD}$, does using a high-flux membrane improve patient survival or reduce CV death, hospitalization, or $\beta_{2}$ microglobulin (B2M) concentration, compared with a low-flux membrane?

\section{Recommendation}

We recommend the use of high-flux dialysis membranes in adult HD patients. However, the cost and availability of high-flux membrane need to be considered.

Recommendation grade: strong recommendation (A)

Level of evidence: high

\section{- Summary of evidence}

To date, three large-scale randomized clinical trials, the HEMO [49], MPO (Membrane Permeability Outcome) [54], and EGE [55] trials, have compared high- vs. low-flux HD membranes. Those trials have not proved a statistically significant benefit in extending patients' lives.
However, the HEMO Study [49] demonstrated a significant reduction in CV death as a secondary endpoint (0.072/ patient $\times$ year vs. $0.059 /$ patient $\times$ year), and a significant benefit in the composite outcome of CV death and hospitalization due to $\mathrm{CV}$ disease. Furthermore, a subgroup analysis showed a significant reduction in mortality risk $(37 \%)$ in patients treated with dialysis for more than 3.7 years prior to randomization. The MPO Study [54] reported a statistically significant reduction in all-cause mortality in the high- vs. the low-flux group among participants with serum albumin equal to or lower than $4 \mathrm{~g} / \mathrm{dL}$ (relative risk [RR], 0.49; 95\% CI, 0.28-0.87). That study also showed that improved survival was associated with high-flux dialyzers among those with diabetes. Although the EGE Study [55] did not show a reduction in composite CV events, a post hoc analysis suggested a benefit associated with highvs. low-flux dialysis in improving CV event-free survival among those with AVF and those with diabetes.

Our meta-analysis of 12 prospective clinical trials [49,54-64] comparing high- vs. low-flux HD membranes, excluding observational studies, showed a $13 \%$ reduction (RR, 0.87; 95\% CI, 0.76-0.99) in all-cause death and a 19\% reduction (RR, 0.81; 95\% CI, 0.70-0.95) in CV death (Supplement 9 forest plots 1.1. and 1.2.). Furthermore, the B2M concentration was reduced by $9.90 \mathrm{mg} / \mathrm{L}$ (Supplement 9 forest plot 1.4.). However, no differences in hospitalization or Kt/V were shown (Supplement 9 forest plots 1.3. and 1.5.).

(Supplement 3 | Review questions-PICO format-Key question 3.1.)

(Supplement 4| Search strategies-Key question 3.1.)

(Supplement 5 | Study selection flow diagrams-Key question 3.1.)

(Supplement 6| Summary evidence tables-Key question 3.1.)

(Supplement 7 | Bias risk assessment-Key question 3.1.)

(Supplement 8 | Clinical evidence profiles (GRADE tables)_Key question 3.1.)

(Supplement 9|Forest plots-Key question 3.1.)

\section{- Recommended considerations}

High-flux dialysis membranes are more expensive than low-flux membranes. The increased cost and potential unavailability of high-flux membrane may be considered in the final decision. 


\section{1) Benefits and harms}

As mentioned above, our meta-analysis of 12 interventional studies showed that high-flux membrane reduced all-cause death by $13 \%$ and also reduced CV deaths and serum B2M. Particularly increased benefits are expected in patients with diabetes and in those with a long duration of dialysis treatment and a high risk of dialysis-related amyloidosis.

High-flux membrane does not elevate the risks of intradialytic hypotension and muscle cramps, nor does it remarkably increase medical costs because high-flux membranes are reimbursed in most cases in the Republic of Korea.

\section{2) Patient values and preferences}

Patients do not have preferences between high- and lowflux HD membranes. The choice of membrane type depends mostly on the medical decision of the clinician.

\section{3) Obstacles, facilitating factors, and measures}

None.

\section{4) Resources}

High-flux membranes are available in most HD centers in the Republic of Korea. They are also reimbursed under the National Health Insurance System.

\section{Key question 3.2 .}

Is online HDF superior to high-flux HD in patient lifespan, CV mortality, hospitalization rate, and quality of life for HD patients?

\section{Recommendation}

1. There was no difference in all-cause mortality, CV mortality, hospitalization rate and quality of life in online hemodiafiltration (HDF) compared with high-flux HD.

Recommendation grade: conditional recommendation (B) Level of evidence: moderate

2. We consider it reasonable to apply high-volume online HDF after considering the cost-effectiveness in some cases.

Recommendation grade: expert consensus

\section{- Summary of evidence}

In randomized clinical trials comparing online HDF and high-flux HD, such as the Turkish OL-HDF (Online Hemo- diafiltration) [65] and the FRENCHIE (French Convective vs. Hemodialysis in the Elderly) [66], no significant effect was demonstrated on overall lifespan or CV mortality (Supplement 9 forest plot 1.1). However, when the participants in the Turkish OL-HDF Study were divided into two groups with a median amount of supplementation of 17.4 L, the high-efficiency group (17.4 L or more) had significantly longer lifespans than the lower efficiency group $(\mathrm{p}=0.03)$.

The ESHOL (Estudio de Supervivencia de Hemodiafiltración On-Line) Study [67], a randomized clinical trial comparing high-efficiency online HDF with HD, showed a $30 \%$ improvement in overall lifespan in the high-flow online HDF group (hazard ratio [HR], 0.70; 95\% CI, 0.53-0.92; $\mathrm{p}=0.01$ ) CV mortality was reduced by $33 \%$ (HR, $0.67 ; 95 \%$ CI, $0.44-1.01 ; \mathrm{p}=0.06) .8 .1 \%$ of the patients in the HD group in this study used low-flux HD membranes.

In both the Turkish OL-HDF and FRENCHIE studies, no difference in the overall hospitalization rate was observed between the two groups (Supplement 9 forest plot 1.2), but in the ESHOL Study, the hospitalization rate was lower in the high-flow online HDF group (RR, 0.78; 95\% CI, 0.67$0.90 ; p=0.001$ ). In terms of quality of life, our meta-analysis of six prospective clinical trials (excluding observational studies) [68-73] found no significant difference between the online HDF and HD groups.

(Supplement 3 | Review questions-PICO format-Key question 3.2.)

(Supplement 4 | Search strategies-Key question 3.2.)

(Supplement 5 | Study selection flow diagrams-Key ques(Supplement 6 | Summary evidence tables-Key question 3.2.) (Supplement 7 | Bias risk assessment-Key question 3.2.) (Supplement 8 | Clinical evidence profiles (GRADE tables) Key question 3.2.)

(Supplement 9 |Forest plots-Key question 3.2.)

\section{- Recommended considerations}

Online HDF is a dialysis method that is advantageous for solute removal by diffusion and convection, but additional large-scale prospective clinical studies are needed to prove its effectiveness in improving several clinical parameters [74-76]. Our recommendation could be changed by the results of a currently ongoing randomized clinical trial [77]. 


\section{1) Benefits and harms}

For online HDF, an HD machine that supports it must be secured. According to the results of previous studies, a large amount of supplementation solution must be used to accrue clinical benefits such as an improvement in the survival rate, and the key to such high-flow online HDF is securing a high blood flow rate. The additional cost burden of online HDF can be a barrier to its implementation.

\section{2) Patient values and preferences}

In the case of online HDF, additional costs are incurred for the patient, so the judgment and explanation of the medical staff and the understanding and consent of the patient are required.

\section{3) Obstacles, facilitating factors, and measures}

Health insurance reimbursement is required.

\section{4) Resources}

A dialysis machine for online HDF and a high-flow dialysis membrane are required.

\section{Chapter 4. Anticoagulation for the hemodialysis}

\section{Key question 4.1.}

In adult HD patients without an increased bleeding risk, does LMWH reduce bleeding events or HD circuit thrombosis, compared with conventional UFH for anticoagulation during HD?

\section{Recommendation}

We recommend using UFH as the standard for systemic anticoagulation in HD patients without an increased bleeding risk because no differences could be found in the bleeding outcomes or circuit thrombosis between UFH and LMWH.

Recommendation grade: strong recommendation (A)

Level of evidence: low

\section{- Summary of evidence}

$\mathrm{UFH}$ is the conventional anticoagulant for HD in patients without active bleeding, a recent history of bleeding events, moderate to severe thrombocytopenia, or heparin allergy. Usually, a loading dose of 1,000-2,000 units is administered at the start of $\mathrm{HD}$, followed by a continuous infusion of 500-1,500 units per hour, which is stopped $\sim 30$ minutes before the end of each HD session. The heparin dose can be adjusted empirically according to the clinical situation. Compared with UFH, LMWH can be administered as a bolus, and it has been shown to be better in terms of lipid profile and osteoporosis. Thus, its use in HD patients is increasing in Europe [78]. We intended to verify whether LMWH could reduce bleeding events or HD circuit thrombosis compared with the conventional UFH in HD patients without a high bleeding risk.

Three meta-analyses that addressed the efficacy and safety of LMWH and UFH were identified at the time of literature search [79-81]. We selected clinical studies with parallel or cross-over designs that randomly allocated patients on HD or HDF into LMWH and UFH groups over at least a 1-month period. Based on those criteria, several studies were excluded from our analysis for the following reasons: less than a 1-week study period (Borm et al. [82], Koutsikos et al. [83] in the meta-analysis by Lim et al. [80] and Palamaner Subash Shantha et al. [81]); a dose finding study design (Ryan et al. [84]); and no random allocation (Al-Saran et al. [85], Bramham et al. [86], Yang et al. [87] in a meta-analysis by Lazrak et al. [79], and Sabry et al. [88]). Our meta-analysis was thus performed with six studies [89-94], though the poor blinding in those studies produced only a moderate level of evidence. The RR for any bleeding event was 0.74 (95\% CI, 0.24-2.31) and did not differ between the LMWH and UFH groups (Supplement 9 forest plot 1.1.). The reported cases of major bleeding were too few to do a subgroup analysis. Circuit thrombosis was defined as the number of cases of clotting in the dialyzer and circuit lines. That meta-analysis used three studies $[90,91,93]$ and produced an RR of 0.99 (95\% CI, 0.56-1.77) for the LMWH group compared with UFH group, indicating no difference between the two anticoagulants (Supplement 9 forest plot 1.2.). However, the level of evidence was assessed to be low due to heterogeneity among the studies and possible risks of bias.

(Supplement 3 | Review questions-PICO format-Key question 4.1.)

(Supplement 4 | Search strategies-Key question 4.1.)

(Supplement 5 | Study selection flow diagrams-Key question 4.1.)

(Supplement 6|Summary evidence tables-Key question 4.1.) 
(Supplement 7 | Bias risk assessment-Key question 4.1.)

(Supplement 8 | Clinical evidence profiles (GRADE tables)_Key question 4.1.)

(Supplement 9|Forest plots-Key question 4.1.)

\section{- Recommended considerations}

\section{1) Benefits and harms}

Previous meta-analyses reported the benefit of LMWH in terms of dyslipidemia and osteoporosis, but neither benefit nor harm was found in the primary outcomes of bleeding and circuit thrombosis, which our question addressed.

\section{2) Patient values and preferences}

In terms of bleeding and circuit thrombosis, the two drugs do not appear to differ in view of patient values and preferences.

\section{3) Obstacles, facilitating factors, and measures}

When the cost of LMWH went down, clinicians and nursing staff would prefer LMWH to UFH because of the convenience of administration and monitoring.

\section{4) Resources}

Dalteparin, enoxaparin, and nadroparin are available in the Republic of Korea. Saltissi et al. [92] reported a cost-effectiveness analysis, but we did not adopt it because of the difference in health system and reimbursement.

\section{- Other considerations}

We recommend UFH as the standard anticoagulant for HD due to the low level of evidence supporting the superiority of LMWH. However, LMWH may be used as an alternative based on clinical decisions regarding disease status of patients, medication, or cost-effectiveness.

\section{Key question 4.2.}

In HD patients with a high risk of bleeding, does regional anticoagulation with nafamostat mesylate attenuate the risk of bleeding and prevent thrombosis in the extracorporeal blood circuit, compared with heparin?

\section{Recommendation}

1. We recommend not to use heparin for anticoagulation in HD patients with a high risk of bleeding.

Recommendation grade: against recommendation (C) Level of evidence: low

2. We suggest the use of nafamostat mesylate, instead of heparin, for anticoagulation in HD patients with a high risk of bleeding.

Recommendation grade: conditional recommendation (B) Level of evidence: low

\section{- Summary of evidence}

Only a few studies conducted in the Republic of Korea presented low-level evidence about the anticoagulation strategy for HD patients with a risk of bleeding.

In a multi-center phase III trial assessing the anticoagulation efficacy and safety of nafamostat mesylate [95], 58 HD patients were defined as at high risk of bleeding due to hemorrhagic complications. Among the 49 patients whose clinical course could be assessed, no one experienced the progression of preexisting hemorrhagic lesions during the use of nafamostat mesylate, and improvement in the preexisting lesions was seen in 37 patients (71\%). On the contrary, in a cross-over arm using heparin in those same patients at preoperative stages or during recovery from a hemorrhagic complication, aggravation of the preexisting lesion was observed in one patient (4\%), and only six patients $(28 \%)$ experienced improvement in the preexisting lesions, with 15 patients (68\%) remaining stationary. Nafamostat mesylate also showed a superior profile to heparin in the degrees of residual blood in the dialyzer and blood clotting in the venous drip chamber. The incidence of adverse reactions was comparable in both groups.

In a randomized trial conducted in a single center in the Republic of Korea [96], 17 HD patients with intracerebral hemorrhage were divided into two groups: one with heparin $(n=9)$, and the other with nafamostat mesylate ( $\mathrm{n}=$ 8). The follow-up computed tomography imaging of the hemorrhagic lesions showed that, compared with heparin, nafamostat mesylate significantly prevented the aggravation of preexisting hemorrhagic lesions ( $p=0.024)$, but no specific descriptions about the formation of blood clots or adverse events were presented in that study.

Despite the lack of large-scale trials, we recommend against using heparin for anticoagulation in HD patients 
with a high risk of bleeding based on the limited evidence that the use of heparin can aggravate preexisting hemorrhagic lesions. Provided that regional anticoagulation with nafamostat mesylate efficiently prevents both the aggravation of preexisting lesions and thrombosis in the extracorporeal blood circuit, we suggest the use of nafamostat mesylate, instead of heparin, for anticoagulation in HD patients with a high risk of bleeding.

(Supplement 3 | Review questions-PICO format-Key question 4.2.)

(Supplement 4 | Search strategies-Key question 4.2.)

(Supplement 5 | Study selection flow diagrams-Key question 4.2.)

(Supplement 6 | Summary evidence tables-Key question 4.2.) (Supplement 7 | Bias risk assessment-Key question 4.2.)

\section{- Recommended considerations}

\section{1) Benefits and harms}

The use of heparin in HD patients with a high risk of bleeding should be minimized because it could aggravate the preexisting hemorrhagic lesions. As no one has reported that the frequency of adverse events is higher in patients with nafamostat mesylate treatment than with heparin treatment, the evidence so far indicates that the use of nafamostat mesylate does not produce further harm in HD patients with a high risk of bleeding.

\section{2) Patient values and preferences}

Because the choice of anticoagulation strategy is usually made by doctor, at least in terms of this key question, it is impractical to consider patient values and preferences.

\section{3) Obstacles, facilitating factors, and measures}

We expect few obstacles to the accommodation of these recommendations because they are largely in accordance with the current practice in the Republic of Korea.

\section{4) Resources}

The National Health Insurance Service covers the use of nafamostat mesylate in HD patients with a high risk of bleeding.

\section{- Other considerations}

Nafamostat mesylate is activated exclusively within the extracorporeal blood circuit because the half-life is only about 8 minutes [97]; and therefore, it could be an option for regional anticoagulation. Though nafamostat mesylate is already widely available in the Republic of Korea, the level of evidence for this recommendation is low because of the lack of large scale, randomized trials.

A practice guideline by the Renal Association published in 2019 [78] recommended that systemic anticoagulation be omitted or minimized in patients with an increased bleeding risk. That guideline presented some alternatives to systemic anticoagulation, including a high blood flow rate $[98,99]$ and using a heparin-coated dialyzer $[100,101]$. Citrate [102] and prostacyclin (epoprostenol) [103] were also presented as regional anticoagulant options. That guideline declared that nafamostat mesylate could not be used in the United Kingdom, suggesting that anticoagulation strategies differ by country. Although physicians are reminded that various regional anticoagulants other than nafamostat mesylate could also be alternatives, we did not thoroughly review those options because we assumed that they would not be easily adopted in the Republic of Korea.

\section{Chapter 5. Volume and fluid status in hemodialysis patients}

\section{Key question 5.1.}

In patients on $\mathrm{HD}$, does limiting interdialytic weight gain (IDWG) between dialysis sessions improve prognosis, compared with not limiting it?

\section{Recommendation}

1. We suggest that the weight-gain ratio between dialysis sessions not exceed $4 \%$ compared with the dry weight before dialysis.

Recommendation grade: strong recommendation (A) Level of evidence: moderate

2. We consider it reasonable that patients whose body weight before dialysis exceeds $4 \%$ compared with the dry weight require an assessment of excess body fluids, dietary compliance, and nutritional status along with the provision of dietary education.

Recommendation grade: expert consensus 


\section{- Summary of evidence}

It is known that excessive weight gain between dialysis sessions can lead to excess fluid volume and increase CV events and mortality by inducing excessive ultrafiltration $[104,105]$. However, weight gain between dialysis sessions can also reflect adequate nutritional intake. Therefore, nephrologists should use a multifactorial assessment to evaluate patients with weight gain between dialysis sessions. According to both the United States Renal Data System [106] and the DOPPS (Dialysis Outcomes and Practice Patterns Study) [107], a large-scale observational study in the early 2000s, were significantly higher than the control group when the ratio of weight gain between dialysis sessions was excessively high compared with the dry weight. Based on those results, the 2015 dialysis treatment guidelines in Japan recommended a weight gain ratio of less than $6 \%$ between dialysis sessions. However, in those studies, the ultrafiltration rate per time of dialysis was not adjusted, the effect size of the mortality risk was small, and the definition of IDWG between dialysis sessions was not unified $[104,105]$.

Weight gain between dialysis sessions is highly correlated with chronic volume overload, but the two concepts are not exactly the same. Recent research results suggest that in patients with large weight gain during dialysis, body fluid levels need to be assessed using methods such as bioimpedance spectroscopy [108]; anemia and nutritional status need to be corrected [109,110]; and individualized approaches need to be used or suggested. One study included 38,614 HD patients who underwent total body fluid assessments, and even when the IDWG between dialysis sessions was low ( $2.4 \%$ or less), patients with chronic volume overload had significantly higher mortality [108]. In the group with a serum albumin level of $3.8 \mathrm{~g} / \mathrm{dL}$ or less in the 2017 Japan DOPPS, the association with death was significant only in the group with weight gain between dialysis sessions of less than $2.4 \%$ [109]. In the study of Lee et al. [111], the weight gain ratio between dialysis sessions was $4.0 \%$ in the dialysis group compared with $2.0 \%$ in the control group, and the dialysis group showed a significant $\mathrm{CV}$ event risk (HR, 1.93) compared with the control group after adjustment for residual renal function. In addition, the frequency of intradialytic hypotension during dialysis increased significantly from $3 \%$ or more of IDWG, and that phenomenon during dialysis was associated with death [112]. Following the observational DOPPS study on the effect of weight gain between dialysis sessions on prognosis was published in 2003, a summary of recent trends and prognosis associated with weight gain between dialysis sessions was published in 2017 [113]. The results of the 2017 DOPPS study, which included about 22,000 patients, showed that compared with 2003 , the number of patients with a high rate of weight gain between dialysis sessions was decreasing. Nephrologists and dialysis staff should examine whether patients with excessive weight gain between dialysis sessions have poor compliance with a low-salt diet and water restrictions and whether that could be causing excessive volume overload $[107,114,115]$. Conversely, patients with low IDWG should be considered for their nutritional status and need for an assessment of intake.

(Supplement 3 | Review questions-PICO format-Key question 5.1.)

(Supplement $4 \mid$ Search strategies-Key question 5.1.)

(Supplement 5 | Study selection flow diagrams-Key question 5.1.)

(Supplement 6|Summary evidence tables-Key question 5.1.) (Supplement 7 | Bias risk assessment-Key question 5.1.)

(Supplement 8 | Clinical evidence profiles (GRADE tables)— Key question 5.1.)

\section{- Recommended considerations}

\section{1) Benefits and harms}

No randomized, controlled studies have examined what proportion of weight gain between dialysis sessions is optimal. Japan's HD guidelines from Japanese Society for Dialysis Therapy were the only overseas HD guidelines we found that presented specific values (within 6\%) [116]. Excessive weight gain between dialysis sessions inevitably leads to an increase in the ultrafiltration rate between dialysis sessions when maintaining the same dry weight, and in many studies, an excessive ultrafiltration rate during dialysis showed a significant association with early death [117-119]. Therefore, the Japanese guidelines for HD provide an ultrafiltration amount per unit time of $15 \mathrm{~mL} / \mathrm{kg} /$ hour, considering the average dialysis time. No randomized study has suggested that the proportion of weight gain between dialysis sessions should be within $4 \%$, so this guideline is based on the results of a prospective observational study conducted in 36 hospitals in the Republic of Korea to examine the association between CV death events in dialysis patients and weight gain between dialysis 
sessions patients. In a 2014 study by Lee et al. [111], the group with weight gain of more than $4.0 \%$ between dialysis sessions had a CV mortality risk 1.93 times that of the group with a weight gain of less than $2.0 \%$ (95\% CI, 1.02-3.64; $\mathrm{p}=0.04$ ). An analysis that corrected for residual renal function using 24 hour urine volume also showed significant results, and the gain could be predicted when the weight gain ratio between dialysis sessions was adjusted to at least $4.0 \%$. However, there is insufficient evidence to indicate how much the weight gain ratio should be lowered between dialysis sessions.

\section{2) Patient values and preferences}

In previous studies, weight gain between dialysis sessions correlated with randomly skipping dialysis sessions or reducing the dialysis time by 10 minutes or more $[107,115]$. Based on those findings $[107,115]$, weight gain between dialysis sessions has often been used as an indicator of patient compliance. The possibility that noncompliance of dialysis patients increases their mortality rate has also been suggested [114], so patients with excessive weight gain during dialysis must receive the dialysis staff's constant attention and monitoring.

\section{3) Obstacles, facilitating factors, and measures}

According to the DOPPS observational study of recent trends and prognosis associated with weight gain between dialysis sessions published in 2017, the number of patients with a high proportion of weight gain between dialysis sessions has decreased compared with the results of the 2003 DOPPS, but there was a difference between the absolute weight gain between dialysis sessions (absolute weight gain) and the relative IDWG (percentage of post-HD weight). In particular, the weight gain ratio between dialysis sessions among Japanese dialysis patients was higher than that in the United States, Australia, and Europe, at more than $5.7 \%$, which is an excessive weight gain ratio. For weight gain between dialysis sessions, the dialysis staff and the patient should consider both the weight gain ratio and the absolute weight gain.

\section{4) Resources}

According to a recent study [108], the use of body composition monitoring increases the survival rate by controlling the dry weight of dialysis patients and assessing whether body fluid is excessive [108]. Patients with excessive weight gain during dialysis might consider using a body composition monitor such as bioimpedance.

\section{- Other considerations}

Although limiting IDWG is a patient-centered factor that reflects compliance with dialysis patients' dietary recommendations, such as a low-salt diet and water restrictions, the ultrafiltration rate prescription during dialysis is a treatment-related factor controlled by dialysis staff. A strict emphasis on weight gain between dialysis sessions can lead to nutritional imbalances. Rather than evaluating weight gain between dialysis sessions as an absolute value, patient compliance, nutritional status, and excess fluid balance should be evaluated using a multifactorial approach, and patients should receive dietary education so that they can maintain an appropriate, healthy dry weight.

\section{Key question 5.2.}

In $\mathrm{HD}$ patients, is low sodium dialysate $(<138 \mathrm{mEq} / \mathrm{L})$ more helpful in avoiding volume overload than conventional sodium dialysate (138-140 mEq/L)?

\section{Recommendation}

We suggest that the change of conventional dialysate sodium $(138-140 \mathrm{mEq} / \mathrm{L})$ to low dialysate sodium (<138 mEq/L) to maintain adequate volume status. Attention should be paid to the possibility of developing intradialytic hypotension and muscle cramps while using low sodium dialysis.

Recommendation grade: conditional recommendation

(B) Level of evidence: moderate

\section{- Summary of evidence}

Sodium and water accumulation lead to volume overload and hypertension, which are major risk factors for left ventricular hypertrophy [120-123]. In dialysis patients, ultrafiltration and antihypertensive drugs are the treatments of choice to remove volume overload and reduce blood pressure, which is often left untreated in clinical situations $[124,125]$. Katzarski et al. [126] reported that $90 \%$ of HD patients could control their blood pressure without antihypertensive drugs if they received long HD $(3 \times 8$ hours/ week) and maintained an ideal dry weight. In addition, some studies that increased the frequency of dialysis above the usual case, effectively controlled blood pressure, and 
edema and left ventricular hypertrophy were also improved $[124,127,128]$.

However, increasing the frequency and time of dialysis is subject to medical insurance restrictions. Therefore, lowering sodium dialysate levels below the conventional levels is one method for removing sodium and water. Even with the conventional sodium concentration in dialysate, sodium moves backward into the body, causing increased blood pressure and water retention and leading to weight gain between dialysis sessions [129]. According to a report from the Republic of Korea, the sodium concentration of dialysate was $140 \mathrm{mEq} / \mathrm{L}, 23 \%$; $138 \mathrm{mEq} / \mathrm{L}, 64 \%$; and $139 \mathrm{mEq} / \mathrm{L}$ [130].

Recently, Dunlop et al. [131] published a meta-analysis about low sodium dialysate ( $\mathrm{Na}$ of $<138 \mathrm{mEq} / \mathrm{L}$ ) compared with neutral ( $\mathrm{Na}$ of $138-140 \mathrm{mEq} / \mathrm{L}$ ) and high sodium dialysate ( $\mathrm{Na}$ of $>140 \mathrm{mEq} / \mathrm{L}$ ) in HD patients. That study showed that low sodium dialysate was associated with decreased weight gain, but the risk of hypotension increased.

We conducted a literature search to compare the effects of conventional and low sodium dialysate on IDWG. We found and reviewed three randomized controlled studies and five before/after studies [132-139]. Low dialysate sodium reduced IDWG (mean difference [MD], $-0.27 \mathrm{~kg}$; $95 \% \mathrm{CI},-0.57$ to $0.17 ; \mathrm{p}=0.01$ ), predialysis blood pressure (MD, $-3.52 ; 95 \% \mathrm{CI},-5.46$ to -1.57 ; $\mathrm{p}=0.0004$ ), and the use of antihypertensive medications (standardized MD, -0.60 ; $95 \% \mathrm{CI},-1.13$ to $-0.07 ; \mathrm{p}=0.03$ ). Low dialysate sodium was associated with a low serum sodium concentration (MD, $-1.59 ; 95 \% \mathrm{CI},-2.40$ to $-0.78 ; \mathrm{p}=0.0001$ ). The use of low sodium dialysate increased side effects such as hypotension, muscle cramps, and headaches during dialysis. Our meta-analysis showed that the frequency of hypotension during dialysis increased significantly (RR, 1.49; 95\% CI, 1.09-2.03; $\mathrm{p}=0.01$ ). Thus, low sodium dialysis solution significantly reduced IDWG and blood pressure before dialysis compared with the group using conventional sodium dialysate.

(Supplement 3 | Review questions-PICO format-Key question 5.2.)

(Supplement $4 \mid$ Search strategies-Key question 5.2.)

(Supplement 5 | Study selection flow diagrams-Key question 5.2.)

(Supplement 6 | Summary evidence tables-Key question
5.2.)

(Supplement 7| Bias risk assessment-Key question 5.2.)

(Supplement 8|Clinical evidence profiles (GRADE tables)— Key question 5.2.)

(Supplement 9 | Forest plots-Key question 5.2.)

\section{- Recommended considerations}

\section{1) Benefits and harms}

Intradialytic hypotension, muscle cramps, and headache are common complications of ultrafiltration during HD therapy. To reduce those side effects, we usually use conventional sodium dialysates (138-140 mEq/L), which keeps the sodium level of the dialysate higher than that of the patient's plasma sodium. When using a low sodium dialysate, the risk of intradialytic hypotension increases, which can lead to increased CV disease and hospitalization rates. Therefore, the use of low sodium dialysate requires staff to pay attention to patient complaints of hypotension and muscle spasms during dialysis.

\section{2) Patient values and preferences}

Low sodium dialysate is more likely to cause hypotension during dialysis, and if hypotension occurs, patients feel that dialysis is unsafe and are more likely to become dissatisfied $[140,141]$.

\section{3) Obstacles, facilitating factors, and measures}

None.

\section{4) Resources}

In a HD center, the use of low sodium dialysate carries no cost increase. Still, caution is required because of the risk of hypotension and muscle cramps during dialysis and increased hospitalization rates.

\section{Chapter 6. Blood pressure control in hemodialysis patients}

\section{Key question 6.1.}

In HD patients, does lowering predialysis systolic blood pressure below $140 \mathrm{mmHg}$ improve patient prognosis? 


\section{Recommendation}

1. There is insufficient evidence to assign an optimal blood pressure target for HD patients. Recommendation grade: inconclusive (I)

Level of evidence: very low

2. We consider it reasonable that antihypertensive medications should be prescribed for hypertensive HD patients considering multi-factors.

Recommendation: expert consensus

\section{- Summary of evidence}

Blood pressure lowering treatment significantly reduces the CV morbidity and mortality rate in HD patients, which is similar to the effects of antihypertensive medication in the general population. However, no optimal blood pressure goal has been suggested for HD patients [142]. Some traits necessitate a careful interpretation of the study results for lowering blood pressure in HD patients. Most RCTs were based on a specific drug, not a target blood pressure. In our systematic review, it was difficult to pool blood pressure targets because the blood pressure reduction achieved by patients varied widely among the trials, and the baseline blood pressure level was heterogenous in each study. Therefore, the evidence is insufficient to determine whether the effect of antihypertensive medication is a drug-specific effect or a result of reducing the blood pressure below a certain threshold.

In one prospective observational cohort study performed in the Republic of Korea, a U-shaped HR pattern of patient mortality was observed among 2,299 HD patients during 4.5 median years of follow-up. The lowest risk was shown in the groups with 130-150 mmHg of systolic blood pressure. When the continuous blood pressure was categorized, the group with systolic blood pressure under $110 \mathrm{mmHg}$ and the group with systolic blood pressure higher than $170 \mathrm{mmHg}$ showed an increased HR for mortality during follow-up [143]. In a Western study of 9,333 HD patients in an observational cohort with a median follow-up of 1.5 years, a similar U-shaped HR pattern for patient mortality was observed; however, the lowest risk in that study was observed at around $165 \mathrm{mmHg}$, which was different from the Korean study [144]. Observational studies of blood pressure and patient mortality in HD patients reported a U-shaped HR, which represents increased short-term mortality risk at the tail sides of the blood pressure distribution.
Nevertheless, that evidence is insufficient to suggest a particular threshold for blood pressure that elevates the shortterm mortality risk. A multi-faceted approach is needed because several factors can act as confounders for blood pressure treatment, including interdialytic blood pressure variability [145], intradialytic antihypertensive drug removal through the dialysis membrane [146], body fluid changes [147], reduced vascular elasticity, and postdialysis blood pressure increases, which can also manifest as intradialytic hypertension [148].

(Supplement 3 | Review questions-PICO format-Key question 6.1.)

(Supplement $4 \mid$ Search strategies-Key question 6.1.)

(Supplement 5 | Study selection flow diagrams-Key question 6.1.)

\section{- Recommended considerations}

\section{1) Benefits and harms}

Although antihypertensive medication reduced CV events and patient mortality rates in HD patients, interdialytic hypotension should be checked. Intradialytic or postdialysis hypotension can lead muscle cramps, dizziness, and an increased risk of falls and fractures.

\section{2) Patient values and preferences}

Patients might refuse hypertension treatment for the previously described reasons. However, uncontrolled hypertension is associated with an increased admission rate for heart failure and can aggravate ventricular hypertrophy, which can worsen heart failure. Therefore, patient education about those risks should be delivered to ensure that they can make informed decisions.

\section{3) Obstacles, facilitating factors, and measures}

Excessive volume gain during the interdialytic period can interfere with optimal blood pressure maintenance through excessive volume reduction during dialysis sessions. A lowsalt diet should be encouraged in MHD patients because salt intake makes patients thirsty, which directly adds to their interdialytic volume gain.

\section{4) Resources}

Home blood pressure monitoring or continuous blood pressure monitoring using an ambulatory blood pres- 
sure monitoring system reported better information than dialysis unit blood pressure measurements $[149,150]$. However, in terms of resource management, it is difficult to recommend that all patients buy and maintain a home blood pressure monitoring system. In addition, no center provides 24-hour continuous ambulatory blood pressure monitoring at this time.

\section{Key question 6.2.}

In HD patients, does the incidence of intradialytic hypotension decrease when the dialysate temperature is lowered below the standard dialysate temperature?

\section{Recommendation}

We suggest lowering the dialysate temperature to reduce intradialytic hypotension.

Recommendation grade: conditional recommendation (B)

Level of evidence: moderate

\section{- Summary of evidence}

Intradialytic hypotension is a common complication and requires appropriate management because it affects the morbidity and mortality rates of HD patients. Several methods have been tried to prevent intradialytic hypotension. One of them is to lower the dialysate temperature. In general, standard temperature dialysis maintains the dialysate temperature at $36.5^{\circ} \mathrm{C}-37.0^{\circ} \mathrm{C}$, which is similar to body temperature. The dialysis methods that lower the dialysate temperature are fixed reduction (usually $35.0^{\circ} \mathrm{C}-35.5^{\circ} \mathrm{C}$ ) and isothermic dialysis through body temperature monitoring using a biofeedback system [151].

According to seven RCTs [152-158] and three prospective studies [159-161], intradialytic hypotension incidence decreased when the dialysate temperature was lowered [152-157,159,160]. In addition, there was little change in blood pressure reduction during or after dialysis, and the lowest blood pressure during dialysis was higher than during standard dialysis [152,153,155-161]. Those effects were more notable in patients who experienced more frequent intradialytic hypotension [156]. When the dialysate temperature was lowered, the incidence of intradialytic hypotension decreased, which in turn decreased regional left ventricular dysfunction and myocardial stunning $[152,158]$. A cold sensation or discomfort tended to increase when the dialysate temperature was lowered, but it was not severe enough to stop dialysis $[152,158]$, and there was no difference in symptoms such as shivering [157]. In fact, in some studies patients reported feeling more energetic when the dialysate temperature was reduced and requested the reduced dialysate temperature for future session [156,160]. In previous studies, the dialysis efficiency, assessed by Kt/V and the URR, did not differ when the dialysate temperature changed $[156,157,159]$. However, no direct comparison has been made of the effects of fixed reduction of dialysate temperature and isothermic dialysate. Most studies related to dialysate temperature have been randomized cross-over trials conducted in relatively few patients for short periods of time. In addition, no study has examined the long-term follow-up results on CV disease and mortality, so a large-scale study is needed to evaluate the major long-term outcomes of lowering the dialysate temperature.

(Supplement 3 | Review questions-PICO format-Key question 6.2.)

(Supplement 4 | Search strategies-Key question 6.2.)

(Supplement 5 | Study selection flow diagrams-Key question 6.2.)

(Supplement 6|Summary evidence tables-Key question 6.2.) (Supplement 7 | Bias risk assessment-Key question 6.2.)

(Supplement 8 | Clinical evidence profiles (GRADE tables)— Key question 6.2.)

\section{- Recommended considerations}

\section{1) Benefits and harms}

Lowering the dialysate temperature is relatively simple and does not incur additional costs compared with standard dialysis. It is considered advantageous because it minimizes intradialytic hypotension, and the risk is not great. A cold sensation or discomfort tended to increase when the dialysate temperature was lowered, but it was not severe enough to stop dialysis. Indeed, in some studies, patients felt more energetic when the dialysate temperature was lowered and requested the reduced dialysate temperature for future sessions. Overall, the risk is not significant.

\section{2) Patient values and preferences}

During dialysis with a lowered dialysate temperature, some patients experience a cold sensation and more shivering. Therefore, clinicians should explain the advantages and 
disadvantages of a fixed reduction in dialysate temperature or isothermal dialysate to the patient and adjust the dialysis method according to the patient's values and preferences.

\section{3) Obstacles, facilitating factors, and measures}

No additional equipment or facilities are required to lower the dialysate temperature. However, if the patient's cold sensation or shivering is severe due to the lower dialysate temperature, which could be an obstacle. Therefore, explain the advantages and disadvantages of dialysis with reduced dialysate temperature or isothermal dialysis to the patients and determine an appropriate method.

\section{4) Resources}

Lowering the dialysate temperature is simple and economical because it does not require any additional equipment or facilities. In addition, because intradialytic hypotension incidence decreases, it can reduce costs by removing the need for further treatments and eliminate the need for additional medical staff when intradialytic hypotension occurs.

\section{- Other considerations}

For this key question, we referenced three systematic review and meta-analysis studies [151,162,163] with their quality assessments, in addition to 10 RCTs and prospective studies.

\section{Chapter 7. Evaluating and monitoring hemodialysis patients}

\section{Key question 7.1.}

What regular test items and frequency are appropriate for patients on MHD?

\section{Recommendation}

1. We consider it reasonable to test dialysis adequacy at least every 3 months in patients on MHD. Recommendation grade: expert consensus

2. We consider it reasonable to perform CBC tests, liver function tests, and routine chemistry tests at least monthly in patients on MHD.

Recommendation grade: expert consensus
3. We consider it reasonable to test iron status, PTH, and $\mathrm{HbA} 1 \mathrm{C}$ (in diabetic patients) and perform a chest radiograph at least every 3 months in patients on MHD. Recommendation grade: expert consensus

4. We consider it reasonable to test hepatitis viral markers and perform electrocardiography at least every 6 months in patients on MHD.

Recommendation grade: expert consensus

\section{- Summary of evidence}

In patients undergoing $\mathrm{HD}$ treatment to treat $\mathrm{CKD}$, the purpose of dialysis is to sufficiently remove uremic substances and water to control uremic symptoms, maintain a stable electrolyte balance, and prevent the deterioration of nutritional status, thereby improving health and quality of life. Maintaining an adequate dialysis dose means maintaining the patient's well-being, adequate volume status, and balanced biochemical levels. Many studies have reported that dialysis adequacy is associated with patient survival and quality of life [49,164-167]. No RCTs or prospective observational studies have reported the outcomes for test items and intervals in patients on MHD. Moreover, no studies have examined Korean patients on MHD. However, a retrospective study recently published in Canada found that routine monthly blood testing of HD patients, compared with testing every 6 weeks, was not associated with a lower risk of death, CV events, or hospitalization during follow-up [168]. In this guideline, the test recommendations above are in accordance with expert opinion, given that most dialysis centers conduct blood tests monthly.

\section{- Global clinical practice guideline}

Previously foreign practice guidelines recommended that the dialysis dose be measured monthly. Most dialysis centers perform blood testing, including electrolytes, monthly because the tests performed in patients undergoing MHD are uncomplicated and inexpensive [169,170]. The KDOQI guideline published in 2006 recommended that the dialysis dose be measured at regular intervals no less than monthly (A). Less frequent measurements could compromise the timeliness with which deficiencies in the delivered dose of $\mathrm{HD}$ are detected and thereby delay the implementation of corrective action [169]. The European best practice guideline published in 2007 also recommended that the delivered dialysis dose be measured at least monthly (Opinion) [170]. 
The UK Renal Association CPG published in 2019 recommends measuring and monitoring the dialysis dose monthly for most center-based dialysis patients (1B) [78]. However, in this guideline, we recommended that the dialysis dose be measured at least every 3 months, which is in accordance with expert agreement and takes into account the medical reality and cost of testing in the Republic of Korea.

In this guideline, $\mathrm{CBC}$, liver function (total protein and albumin levels), and routine blood chemistry (blood urea nitrogen [BUN], creatinine [Cr], sodium, potassium, calcium, phosphate, uric acid, and glucose) tests are recommended at least monthly. Most HD centers in the Republic of Korea already perform those blood tests monthly. Moreover, the 2012 Kidney Disease: Improving Global Outcomes (KDIGO) CPG for anemia in CKD recommends that the hemoglobin $(\mathrm{Hb})$ concentration be measured at least monthly in patients with CKD stage 5D [171]. In this guideline, our recommendations reflect and apply those guidelines to Korean patients on MHD.

Because the KDIGO 2017 CPG update for CKD-mineral bone disorder deems it reasonable to monitor PTH every 3-6 months in patients with CKD stage 5D [172,173], we recommended monitoring PTH at least every 3 months. Because other guidelines, including the KDIGO guideline, suggest screening patients on dialysis for hepatitis virus infection every 6 months [174-176], we accept that recommendation as an expert agreement in this guideline.

(Supplement 3 | Review questions-PICO format-Key question 7.1.)

(Supplement $4 \mid$ Search strategies-Key question 7.1.)

(Supplement 5 | Study selection flow diagrams-Key question 7.1.)

(Supplement 6|Summary evidence tables-Key question 7.1.)

\section{- Recommended considerations}

1) Benefits and harms

In patients on MHD, routine examinations according to the above recommendations carry no risks compared with their delayed administration. However, it is necessary to consider the cost of the testing, medical devices, and providers. For patients with residual renal function, residual renal function and process tests should also be considered.

\section{2) Patient values and preferences}

Laboratory tests are generally performed monthly in dialysis units for patients on MHD, and the test for dialysis adequacy is uncomplicated. For the other tests recommended above, we expect little difficulty if physicians adequately explain why tests for PTH, chest radiographs, and electrocardiograms are needed.

\section{3) Obstacles, facilitating factors, and measures}

Although the testing and cost could be obstacles, they can be overcome by convincing patients that the tests are a necessary process to optimize their prescription and improve their survival.

\section{4) Resources}

Laboratory tests are already performed in most dialysis centers, and modifying dialysis prescriptions based on the results of laboratory testing leads to better survival and quality of life in patients on MHD.

\section{- Other considerations}

Table 4. Recommendations for test items and intervals in patients on MHD

\begin{tabular}{ll}
\hline Test items & Intervals \\
\hline - Complete blood test (Hb, platelets) & At least monthly \\
- Liver function test (total protein, albumin) & \\
- Blood chemistry (BUN/Cr, Na/K, Ca/P, & \\
uric acid, glucose) & At least every 3 months \\
- Dialysis adequacy & \\
- Iron status (ferritin, Fe/total iron binding & \\
capacity) & \\
- PTH & \\
- Glycated Hb (HbA1C, in patients with & \\
diabetes) & \\
- Chest radiograph & \\
- Hepatitis virus test (hepatitis C virus, & At least every 6 months \\
antihepatitis C virus) & \\
- Electrocardiography
\end{tabular}

\section{Chapter 8. Nonstandard settings of hemodialysis (elderly, children)}

\section{Key question 8.1.}

In elderly patients with ESKD, does dialysis initiation affect the survival rate compared with conservative treatment? 


\section{Recommendation}

1. We suggest that preparation for appropriate renal replacement therapy be considered for elderly patients who progress to ESKD.

Recommendation grade: conditional recommendation (B) Level of evidence: moderate

2. We consider it reasonable that in elderly patients with ESKD, the optimal treatment should find an individualized balance between appropriate renal replacement therapy and conservative treatment.

Recommendation grade: expert consensus

\section{- Summary of evidence}

With advances in renal replacement therapy, the overall survival rate of patients with ESKD is improving, but it is not yet clear whether the implementation of renal replacement therapy, compared with conservative treatment, has any survival benefit in elderly patients. Randomized controlled studies to answer that question could not be performed ethically. Comparing any dialysis group with any conservative treatment group would raise difficult issues in interpreting the selection bias for elderly patients placed in the relatively healthy group, the lead-time bias of the patients receiving dialysis, and the lack of reference studies of patients receiving conservative treatment. A meta-analysis of 89 observational studies on elderly patients with ESKD from 1976 to 2014, including a total of 294,921 patients, reported 1-year survival rates of $77.9 \%$ in the HD group and $70.6 \%$ in the conservative treatment group. Although that report suggested the possibility that HD offered a survival benefit [177], it was insufficient to judge the role of conservative treatment because only 724 of the patients $(0.2 \%)$ were included in the conservative treatment group. In a meta-analysis in 2017, the dialysis group showed a better survival rate than the conservative treatment group ( $\mathrm{HR}, 0.53 ; 95 \% \mathrm{CI}, 0.30-0.91 ; \mathrm{p}=0.02$ ), but there was significant heterogeneity among studies [178]. Most of the studies from before 2010 included in the meta-analyses were small and retrospective [179-181], and one small prospective study did not distinguish HD from peritoneal dialysis [182].

In prospective observational studies of elderly patients since 2015, dialysis treatment showed benefits over conservative treatment in the entire patient group [183-185], although comorbidities increased [183] and the benefit was not significant in patients older than 85 years [184] or 80 years [185]. In retrospective studies, the benefit of dialysis was greater than that of conservative treatment, but setting an appropriate control group would be important [186-188]. A Canadian study of reimbursement data using propensity score matching showed a benefit of dialysis in the first 3 years ( $\mathrm{HR}, 0.59 ; 95 \% \mathrm{CI}, 0.46-0.77$; $\mathrm{p}<0.001$ ), but no difference between dialysis and conservative treatment after that [188]. For this practice guideline, we conducted a meta-analysis of 11 studies to synthesize evidence from the above studies, in which the mean age of elderly patients in the dialysis group was $76.0 \pm 5.3$ years. The result of our meta-analysis showed that dialysis was more beneficial than conservative treatment in elderly patients (HR, 0.42; 95\% CI, 0.37-0.47; p < 0.001). As the evidence for survival gains from dialysis treatment is being strengthened $[189,190]$, preparations for appropriate renal replacement therapy are needed when elderly patients progress to ESKD.

(Supplement 3 | Review questions-PICO format-Key question 8.1.)

(Supplement 4| Search strategies-Key question 8.1.)

(Supplement 5 | Study selection flow diagrams-Key question 8.1.)

(Supplement 6| Summary evidence tables-Key question 8.1.)

(Supplement $7 \mid$ Bias risk assessment-Key question 8.1.)

(Supplement 8 | Clinical evidence profiles (GRADE tables)— Key question 8.1.)

(Supplement 9|Forest plots-Key question 8.1.)

\section{- Recommended considerations}

\section{1) Benefits and harms}

Combining the evidence to date with the results of recent studies suggests that elderly patients with ESKD receive a survival benefit from dialysis treatment. However, some studies have reported longer hospital stays in the dialysis treatment group than the conservative treatment group. In one study, the dialysis treatment group survived for an additional 2 years, but $47.5 \%$ of that survival period was spent at the hospital, whereas the conservative treatment group spent $4.3 \%$ of the survival period at the hospital [182]. This trend was also found in a Canadian study of claims data in 2020; the dialysis treatment group spent 36.25 person-years in the hospital, whereas the conservative treatment group 
spent only 14.65 person-years in the hospital [190]. Further research is needed on the possibility of potential harms, such as prolonged hospitalization periods, decreases in quality of life, and increased medical expenses.

\section{2) Patient values and preferences}

Most elderly people are being cared for by family members or acquaintances, and caregivers are essential in renal replacement therapy for patients with ESKD who have physical, mental, or cognitive difficulties. Attempts should be made to determine whether to start renal replacement therapy by reflecting patient values and preferences as well as those of close family members or caregivers, especially with elderly patients. Leaving aside one study that did not distinguish between types of dialysis [188] and another study that considered only HD [187], HD accounted for $70 \%-80 \%$ of dialysis treatments studied [183-186]. In 2015, Han et al. [191] examined claims data and reported that HD had a more favorable prognosis than peritoneal dialysis as renal replacement therapy for elderly patients (HR, 1.20; 95\% CI, 1.13-1.28). The decision about whether to apply replacement therapy should be made with family members and caregivers, rather than deciding based on age alone, and the type and extent of comorbid injuries, such as cognitive impairment and cerebrovascular disease, should also be considered during the shared decision making.

\section{3) Obstacles, facilitating factors, and measures}

When the decision is made to administer conservative treatment without dialysis, guidelines are needed for providing the best conservative treatment for these patients.

\section{4) Resources}

Compared with conservative treatment, research on the rise of medical costs and quality of life of caregivers for elderly patients receiving dialysis treatment is lacking, so further studies on social costs are needed.

\section{- Other considerations}

Because the definition of elderly patients varied in the studies used in our synthesis of evidence for this recommendation, care should be taken when applying it to patients.

\section{Key question 8.2.}

What is the appropriate nurse-to-patient ratio in pediatric HD?

\section{Recommendation}

1. For HD of children younger than 5 years old, we consider it reasonable that the minimal nurse-to-patient ratio be 1:1. Recommendation grade: expert consensus

2. For HD of older children, we consider it reasonable that the minimal nurse-to-patient ratio be 1:2.

Recommendation grade: expert consensus

\section{- Summary of evidence}

Dialysis of infants and children requires exceptional skill and expertise. Pediatric HD requires devices appropriate for the patient's body size, neonatal or pediatric dosages of medications, proper management of vascular access problems, and meticulous monitoring of volume status and vital signs. Infants and young children undergoing HD are very sensitive to small changes in body water volume or blood pressure because their effective blood volume is smaller than that of adults [192]. Because children might not recognize or verbally express the symptoms of side effects of HD, vital signs should be measured more frequently, and pediatric patients need to be monitored more carefully than adults during HD. For safe HD of children, more frequent clinical assessment is necessary [193]. Therefore, HD for children often requires a nurse-to-patient ratio of 1:1 [194]. Although no CPG has been released [195], a survey of clinical practice in the United Kingdom reported that the usual nurse-to-patient ratio was 1:1 for HD of children younger than 5 years old and 1:2-1:3 for older children at most centers [196]. For HD of young children or patients with significant neurocognitive disability, a nurse-to-patient ratio of $1: 1$ is required. An infant might need the care of two nurses. HD requiring isolation also requires the allocation of one nurse per patient. For children who can communicate or adolescents whose development is normal, a nurseto-patient ratio of 1:2 might be safe. For pediatric dialysis, there should be at least two registered nurses on duty, and the nurse-to-patient ratio should be 1:2 or higher [197].

(Supplement 3 | Review questions-PICO format-Key question 8.2.) 
(Supplement 4| Search strategies-Key question 8.2.)

(Supplement 5 | Study selection flow diagrams-Key question 8.2.)

(Supplement 6|Summary evidence tables-Key question 8.2.)

\section{- Recommended considerations}

\section{1) Benefits and harms}

According to a study of adult patients, the side effects of HD and short-term mortality decreased when the nurse-to-patient ratio increased [198]. Considering that pediatric HD requires more nursing, benefits are expected, and harm is not expected.

\section{2) Patient values and preferences}

Pediatric dialysis needs to take into account the growth and development of the patient, and the family, including siblings, needs support. Therefore, a higher nurse-to-patient ratio is in line with patient values and preferences.

\section{3) Obstacles, facilitating factors, and measures}

Because the predefined medical fee for pediatric HD is the same as for adults in the Republic of Korea, the cost can be an obstacle to having a higher nurse-to-patient ratio for pediatric HD. Therefore, to ensure safe HD for children, a separate medical fee system for pediatric HD is required.

\section{4) Resources}

Not applicable.

\section{Supplementary Materials}

Supplementary data are available at Kidney Research and Clinical Practice online (https://doi.org/10.23876/j.krcp.21.600).

\section{ORCID}

Ji Yong Jung, https://orcid.org/0000-0003-1271-8012 Kyung Don Yoo, https://orcid.org/0000-0001-6545-6517 Eunjeong Kang, https://orcid.org/ 0000-0002-2191-2784 Hee Gyung Kang, https://orcid.org/ 0000-0001-8323-5320 Su Hyun Kim, https://orcid.org/ 0000-0003-3382-528X Hyoungnae Kim, https://orcid.org/ 0000-0002-5359-0214 Hyo Jin Kim, https://orcid.org/0000-0001-9289-9073 Tae-Jin Park, https://orcid.org/ 0000-0003-2631-2953 Sang Heon Suh, https://orcid.org/0000-0003-3076-3466
Jong Cheol Jeong, https://orcid.org/0000-0003-0301-7644 Ji-Young Choi, https://orcid.org/ 0000-0002-9774-3665 Young-Hwan Hwang, https://orcid.org/0000-0001-8935-2659 Miyoung Choi, https://orcid.org/0000-0002-2424-9965 Yae Lim Kim, https://orcid.org/0000-0002-4316-9696 Kook-Hwan Oh, https://orcid.org/ 0000-0001-9525-2179

\section{References}

1. Cooper BA, Branley P, Bulfone L, et al. A randomized, controlled trial of early versus late initiation of dialysis. N Engl J Med 2010;363:609-619.

2. Collins J, Cooper B, Branley P, et al. Outcomes of patients with planned initiation of hemodialysis in the IDEAL trial. Contrib Nephrol 2011;171:1-9.

3. Harris A, Cooper BA, Li JJ, et al. Cost-effectiveness of initiating dialysis early: a randomized controlled trial. Am J Kidney Dis 2011;57:707-715.

4. Whalley GA, Marwick TH, Doughty RN, et al. Effect of early initiation of dialysis on cardiac structure and function: results from the echo substudy of the IDEAL trial. Am J Kidney Dis 2013;61:262-270.

5. Korevaar JC, Jansen MA, Dekker FW, et al. When to initiate dialysis: effect of proposed US guidelines on survival. Lancet 2001;358:1046-1050.

6. Traynor JP, Simpson K, Geddes CC, Deighan CJ, Fox JG. Early initiation of dialysis fails to prolong survival in patients with endstage renal failure. J Am Soc Nephrol 2002;13:2125-2132.

7. Kazmi WH, Gilbertson DT, Obrador GT, et al. Effect of comorbidity on the increased mortality associated with early initiation of dialysis. Am J Kidney Dis 2005;46:887-896.

8. Hwang SJ, Yang WC, Lin MY, Mau LW, Chen HC; Taiwan Society of Nephrology. Impact of the clinical conditions at dialysis initiation on mortality in incident haemodialysis patients: a national cohort study in Taiwan. Nephrol Dial Transplant 2010;25:26162624.

9. Lassalle M, Labeeuw M, Frimat L, et al. Age and comorbidity may explain the paradoxical association of an early dialysis start with poor survival. Kidney Int 2010;77:700-707.

10. Wright S, Klausner D, Baird B, et al. Timing of dialysis initiation and survival in ESRD. Clin J Am Soc Nephrol 2010;5:1828-1835.

11. Clark WF, Na Y, Rosansky SJ, et al. Association between estimated glomerular filtration rate at initiation of dialysis and mortality. CMAJ 2011;183:47-53.

12. Chang JH, Rim MY, Sung J, et al. Early start of dialysis has no sur- 
vival benefit in end-stage renal disease patients. J Korean Med Sci 2012;27:1177-1181.

13. Zhang Y, Hu C, Bian Z, Chen P. Impact of timing of initiation of dialysis on long-term prognosis of patients undergoing hemodialysis. Exp Ther Med 2018;16:1209-1215.

14. Susantitaphong P, Altamimi S, Ashkar M, et al. GFR at initiation of dialysis and mortality in CKD: a meta-analysis. Am J Kidney Dis 2012;59:829-840.

15. Kim DH, Park JI, Lee JP, et al. The effects of vascular access types on the survival and quality of life and depression in the incident hemodialysis patients. Ren Fail 2020;42:30-39.

16. Ozeki T, Shimizu H, Fujita Y, et al. The type of vascular access and the incidence of mortality in Japanese dialysis patients. Intern Med 2017;56:481-485.

17. Bae E, Lee H, Kim DK, et al. Autologous arteriovenous fistula is associated with superior outcomes in elderly hemodialysis patients. BMC Nephrol 2018;19:306.

18. Yeh LM, Chiu SY, Lai PC. The impact of vascular access types on hemodialysis patient long-term survival. Sci Rep 2019;9:10708.

19. Lok CE, Huber TS, Lee T, et al. KDOQI Clinical Practice Guideline for Vascular Access: 2019 update. Am J Kidney Dis 2020;75(4 Suppl 2):S1-S164.

20. Shechter SM, Skandari MR, Zalunardo N. Timing of arteriovenous fistula creation in patients with CKD: a decision analysis. Am J Kidney Dis 2014;63:95-103.

21. Locham S, Naazie I, Canner J, Siracuse J, Al-Nouri O, Malas M. Incidence and risk factors of sepsis in hemodialysis patients in the United States. J Vasc Surg 2021;73:1016-1021.

22. Miyamoto M, Kurita N, Suemitsu K, Murakami M. Fistula and survival outcomes after fistula creation among predialysis chronic kidney disease stage 5 patients. Am J Nephrol 2017;45:356-364.

23. Leermakers JJ, Bode AS, Vaidya A, van der Sande FM, Evers SM, Tordoir JH. Cost-effectiveness of vascular access for haemodialysis: arteriovenous fistulas versus arteriovenous grafts. Eur J Vasc Endovasc Surg 2013;45:84-92.

24. Hall RK, Myers ER, Rosas SE, O’Hare AM, Colón-Emeric CS. Choice of hemodialysis access in older adults: a cost-effectiveness analysis. Clin J Am Soc Nephrol 2017;12:947-954.

25. Dember LM, Lacson E Jr, Brunelli SM, et al. The TiME trial: a fully embedded, cluster-randomized, pragmatic trial of hemodialysis session duration. J Am Soc Nephrol 2019;30:890-903.

26. Lowrie EG, Laird NM, Parker TF, Sargent JA. Effect of the hemodialysis prescription of patient morbidity: report from the National Cooperative Dialysis Study. N Engl J Med 1981;305:1176-
1181.

27. Brunelli SM, Chertow GM, Ankers ED, Lowrie EG, Thadhani R. Shorter dialysis times are associated with higher mortality among incident hemodialysis patients. Kidney Int 2010;77:630636.

28. Flythe JE, Curhan GC, Brunelli SM. Shorter length dialysis sessions are associated with increased mortality, independent of body weight. Kidney Int 2013;83:104-113.

29. Shinzato T, Nakai S, Akiba T, et al. Survival in long-term haemodialysis patients: results from the annual survey of the Japanese Society for Dialysis Therapy. Nephrol Dial Transplant 1997;12:884-888.

30. Tentori F, Zhang J, Li Y, et al. Longer dialysis session length is associated with better intermediate outcomes and survival among patients on in-center three times per week hemodialysis: results from the Dialysis Outcomes and Practice Patterns Study (DOPPS). Nephrol Dial Transplant 2012;27:4180-4188.

31. Shemin D, Bostom AG, Laliberty P, Dworkin LD. Residual renal function and mortality risk in hemodialysis patients. Am J Kidney Dis 2001;38:85-90.

32. Charra B, Calemard M, Laurent G. Importance of treatment time and blood pressure control in achieving long-term survival on dialysis. Am J Nephrol 1996;16:35-44.

33. Marshall MR, Byrne BG, Kerr PG, McDonald SP. Associations of hemodialysis dose and session length with mortality risk in Australian and New Zealand patients. Kidney Int 2006;69:1229-1236.

34. Hwang HS, Hong YA, Yoon HE, et al. Comparison of clinical outcome between twice-weekly and thrice-weekly hemodialysis in patients with residual kidney function. Medicine (Baltimore) 2016;95:e2767.

35. Lin X, Gu L, Zhu M, et al. Clinical outcome of twice-weekly hemodialysis patients with long-term dialysis vintage. Kidney Blood Press Res 2018;43:1104-1112.

36. Sun Y, Wang Y, Yu W, Zhuo Y, Yuan Q, Wu X. Association of dose and frequency on the survival of patients on maintenance of hemodialysis in China: a Kaplan-Meier and Cox-proportional hazard model analysis. Med Sci Monit 2018;24:5329-5337.

37. Obi Y, Eriguchi R, Ou SM, Rhee CM, Kalantar-Zadeh K. What is known and unknown about twice-weekly hemodialysis. Blood Purif 2015;40:298-305.

38. Vanholder R, Van Biesen W, Lameire N. Is starting hemodialysis on a twice-weekly regimen a valid option? Am J Kidney Dis 2014;64:165-167.

39. Held PJ, Port FK, Wolfe RA, et al. The dose of hemodialysis and patient mortality. Kidney Int 1996;50:550-556. 
40. Bloembergen WE, Stannard DC, Port FK, et al. Relationship of dose of hemodialysis and cause-specific mortality. Kidney Int 1996;50:557-565.

41. Chertow GM, Owen WF, Lazarus JM, Lew NL, Lowrie EG. Exploring the reverse J-shaped curve between urea reduction ratio and mortality. Kidney Int 1999;56:1872-1878.

42. Wolfe RA, Ashby VB, Daugirdas JT, Agodoa LY, Jones CA, Port FK. Body size, dose of hemodialysis, and mortality. Am J Kidney Dis 2000;35:80-88.

43. Port FK, Ashby VB, Dhingra RK, Roys EC, Wolfe RA. Dialysis dose and body mass index are strongly associated with survival in hemodialysis patients. J Am Soc Nephrol 2002;13:1061-1066.

44. Salahudeen AK, Dykes P, May W. Risk factors for higher mortality at the highest levels of spKt/V in haemodialysis patients. Nephrol Dial Transplant 2003;18:1339-1344.

45. Termorshuizen F, Dekker FW, van Manen JG, et al. Relative contribution of residual renal function and different measures of adequacy to survival in hemodialysis patients: an analysis of the Netherlands Cooperative Study on the Adequacy of Dialysis (NECOSAD)-2. J Am Soc Nephrol 2004;15:1061-1070.

46. Port FK, Wolfe RA, Hulbert-Shearon TE, McCullough KP, Ashby VB, Held PJ. High dialysis dose is associated with lower mortality among women but not among men. Am J Kidney Dis 2004;43:1014-1023.

47. Ramirez SP, Kapke A, Port FK, et al. Dialysis dose scaled to body surface area and size-adjusted, sex-specific patient mortality. Clin J Am Soc Nephrol 2012;7:1977-1987.

48. Hong WP, Lee YJ. The association of dialysis adequacy, body mass index, and mortality among hemodialysis patients. BMC Nephrol 2019;20:382.

49. Eknoyan G, Beck GJ, Cheung AK, et al. Effect of dialysis dose and membrane flux in maintenance hemodialysis. $N$ Engl J Med 2002;347:2010-2019.

50. Daugirdas JT, Depner TA, Gotch FA, et al. Comparison of methods to predict equilibrated Kt/V in the HEMO Pilot Study. Kidney Int 1997;52:1395-1405.

51. Daugirdas JT, Depner TA, Greene T, et al. Standard Kt/Vurea: a method of calculation that includes effects of fluid removal and residual kidney clearance. Kidney Int 2010;77:637-644.

52. Pattharanitima P, Chauhan K, El Shamy O, et al. The association of standard Kt/V and surface area-normalized standard Kt/V with clinical outcomes in hemodialysis patients. Hemodial Int 2020;24:495-505.

53. Rivara MB, Ravel V, Streja E, et al. Weekly standard Kt/Vurea and clinical outcomes in home and in-center hemodialysis. Clin J
Am Soc Nephrol 2018;13:445-455.

54. Locatelli F, Martin-Malo A, Hannedouche T, et al. Effect of membrane permeability on survival of hemodialysis patients. J Am Soc Nephrol 2009;20:645-654.

55. Asci G, Tz H, Ozkahya M, et al. The impact of membrane permeability and dialysate purity on cardiovascular outcomes. J Am Soc Nephrol 2013;24:1014-1023.

56. Ayli M, Ayli D, Azak A, et al. The effect of high-flux hemodialysis on dialysis-associated amyloidosis. Ren Fail 2005;27:31-34.

57. Chazot C, Kirchgessner J, Pham J, et al. Effect of membrane permeability on cardiovascular risk factors and $\beta 2 \mathrm{~m}$ plasma levels in patients on long-term haemodialysis: a randomised crossover trial. Nephron 2015;129:269-275.

58. Klemm A, Franke C, Busch M, et al. Influence of hemodialysis membrane permeability on serum levels of advanced glycation end products (AGEs) and homocysteine metabolites. Clin Nephrol 2004;61:191-197.

59. Küchle C, Fricke H, Held E, Schiffl H. High-flux hemodialysis postpones clinical manifestation of dialysis-related amyloidosis. Am J Nephrol 1996;16:484-488.

60. Lang SM, Bergner A, Töpfer M, Schiffl H. Preservation of residual renal function in dialysis patients: effects of dialysis-technique-related factors. Perit Dial Int 2001;21:52-57.

61. Li PK, Cheng YL, Leung CB, et al. Effect of membrane permeability on inflammation and arterial stiffness: a randomized trial. Clin J Am Soc Nephrol 2010;5:652-658.

62. Locatelli F, Andrulli S, Pecchini F, et al. Effect of high-flux dialysis on the anaemia of haemodialysis patients. Nephrol Dial Transplant 2000;15:1399-1409.

63. Locatelli F, Mastrangelo F, Redaelli B, et al. Effects of different membranes and dialysis technologies on patient treatment tolerance and nutritional parameters. The Italian Cooperative Dialysis Study Group. Kidney Int 1996;50:1293-1302.

64. Simon P, Ang KS, Cam G, Benziane A, Bonn F. Indices of adequate dialysis in patients hemodialyzed with AN 69 membrane. Kidney Int Suppl 1993;41:S291-S295.

65. Ok E, Asci G, Toz H, et al. Mortality and cardiovascular events in online haemodiafiltration (OL-HDF) compared with high-flux dialysis: results from the Turkish OL-HDF Study. Nephrol Dial Transplant 2013;28:192-202.

66. Morena M, Jaussent A, Chalabi L, et al. Treatment tolerance and patient-reported outcomes favor online hemodiafiltration compared to high-flux hemodialysis in the elderly. Kidney Int 2017;91:1495-1509.

67. Maduell F, Moreso F, Pons M, et al. High-efficiency postdilution 
online hemodiafiltration reduces all-cause mortality in hemodialysis patients. J Am Soc Nephrol 2013;24:487-497.

68. Suwabe T, Barrera-Flores FJ, Rodriguez-Gutierrez R, Ubara Y, Takaichi K. Effect of online hemodiafiltration compared with hemodialysis on quality of life in patients with ESRD: a systematic review and meta-analysis of randomized trials. PLoS One 2018;13:e0205037.

69. Kantartzi K, Panagoutsos S, Mourvati E, et al. Can dialysis modality influence quality of life in chronic hemodialysis patients?: low-flux hemodialysis versus high-flux hemodiafiltration: a cross-over study. Ren Fail 2013;35:216-221.

70. Karkar A, Abdelrahman M, Locatelli F. A randomized trial on health-related patient satisfaction level with high-efficiency online hemodiafiltration versus high-flux dialysis. Blood Purif 2015;40:84-91.

71. Mazairac AH, de Wit GA, Grooteman MP, et al. Effect of hemodiafiltration on quality of life over time. Clin J Am Soc Nephrol 2013;8:82-89.

72. Smith JR, Zimmer N, Bell E, Francq BG, McConnachie A, Mactier R. A randomized, single-blind, crossover trial of recovery time in high-flux hemodialysis and hemodiafiltration. Am J Kidney Dis 2017;69:762-770.

73. Ward RA, Schmidt B, Hullin J, Hillebrand GF, Samtleben W. A comparison of on-line hemodiafiltration and high-flux hemodialysis: a prospective clinical study. J Am Soc Nephrol 2000;11:2344-2350.

74. Nistor I, Palmer SC, Craig JC, et al. Haemodiafiltration, haemofiltration and haemodialysis for end-stage kidney disease. Cochrane Database Syst Rev 2015;(5):CD006258.

75. National Kidney Foundation. KDOQI Clinical Practice Guideline for Hemodialysis Adequacy: 2015 update. Am J Kidney Dis 2015;66:884-930.

76. Nistor I, Palmer SC, Craig JC, et al. Convective versus diffusive dialysis therapies for chronic kidney failure: an updated systematic review of randomized controlled trials. Am J Kidney Dis 2014;63:954-967.

77. H4RT Study Team. The High-volume Haemodiafiltration vs High-flux Haemodialysis Registry Trial [Internet]. Bristol (UK): University of Bristol, c2020 [updated 2020 Aug 5]. Available from: https://www.bristol.ac.uk/population-health-sciences/ projects/h4rt-trial/.

78. Ashby D, Borman N, Burton J, et al. Renal Association Clinical Practice Guideline on Haemodialysis. BMC Nephrol 2019;20:379.

79. Lazrak HH, René É, Elftouh N, Leblanc M, Lafrance JP. Safety of low-molecular-weight heparin compared to unfractionated heparin in hemodialysis: a systematic review and meta-analysis. BMC Nephrol 2017;18:187.

80. Lim W, Cook DJ, Crowther MA. Safety and efficacy of low molecular weight heparins for hemodialysis in patients with end-stage renal failure: a meta-analysis of randomized trials. J Am Soc Nephrol 2004;15:3192-3206.

81. Palamaner Subash Shantha G, Kumar AA, Sethi M, Khanna RC, Pancholy SB. Efficacy and safety of low molecular weight heparin compared to unfractionated heparin for chronic outpatient hemodialysis in end stage renal disease: systematic review and meta-analysis. PeerJ 2015;3:e835.

82. Borm JJ, Krediet R, Sturk A, ten Cate JW. Heparin versus low molecular weight heparin K 2165 in chronic hemodialysis patients: a randomized cross-over study. Haemostasis 1986;16 Suppl 2:59-68.

83. Koutsikos D, Fourtounas C, Kapetanaki A, et al. A cross-over study of a new low molecular weight heparin (Logiparin) in hemodialysis. Int J Artif Organs 1996;19:467-471.

84. Ryan KE, Lane DA, Flynn A, Shepperd J, Ireland HA, Curtis JR. Dose finding study of a low molecular weight heparin, Innohep, in haemodialysis. Thromb Haemost 1991;66:277-282.

85. Al-Saran KA, Sabry A, Taha M, Ghafour MA, Al Fawzan F. Profile of low molecular weight tinzaparin sodium for anticoagulation during hemodialysis. Saudi J Kidney Dis Transpl 2010;21:43-49.

86. Bramham K, Varrier M, Asgari E, Makanjuola D. Comparison of Tinzaparin and unfractionated heparin as anticoagulation on haemodialysis: equal safety, efficacy and economical parity. Nephron Clin Pract 2008;110:c107-c113.

87. Yang C, Wu T, Huang C. Low molecular weight heparin reduces triglyceride, VLDL and cholesterol/HDL levels in hyperlipidemic diabetic patients on hemodialysis. Am J Nephrol 1998;18:384390.

88. Sabry A, Taha M, Nada M, Al Fawzan F, Alsaran K. Anticoagulation therapy during haemodialysis: a comparative study between two heparin regimens. Blood Coagul Fibrinolysis 2009;20:57-62.

89. Bambauer R, Rücker S, Weber U, Köhler M. Comparison of low molecular weight heparin and standard heparin in hemodialysis. ASAIO Trans 1990;36:M646-M649.

90. Lord H, Jean N, Dumont M, Kassis J, Leblanc M. Comparison between tinzaparin and standard heparin for chronic hemodialysis in a Canadian center. Am J Nephrol 2002;22:58-66.

91. Nurmohamed MT, ten Cate J, Stevens P, Hoek JA, Lins RL, ten Cate JW. Long-term efficacy and safety of a low molecular weight heparin in chronic hemodialysis patients: a comparison 
with standard heparin. ASAIO Trans 1991;37:M459-M461.

92. Saltissi D, Morgan C, Westhuyzen J, Healy H. Comparison of low-molecular-weight heparin (enoxaparin sodium) and standard unfractionated heparin for haemodialysis anticoagulation. Nephrol Dial Transplant 1999;14:2698-2703.

93. Schrader J, Stibbe W, Armstrong VW, et al. Comparison of low molecular weight heparin to standard heparin in hemodialysis/ hemofiltration. Kidney Int 1988;33:890-896.

94. Stefoni S, Cianciolo G, Donati G, et al. Standard heparin versus low-molecular-weight heparin: a medium-term comparison in hemodialysis. Nephron 2002;92:589-600.

95. Kim HC, Han SY, Kim HK, et al. A multi-center phase III clinical trial to assess the influence to bleeding and anticoagulant effect of nafamostat mesilate (Futhan) in hemodialysis patients with high bleeding-risk. Korean J Nephrol 2004;23:920- 926.

96. Yang JW, Han BG, Kim BR, et al. Superior outcome of nafamostat mesilate as an anticoagulant in patients undergoing maintenance hemodialysis with intracerebral hemorrhage. Ren Fail 2009;31:668-675.

97. Akizawa T, Koshikawa S, Ota K, Kazama M, Mimura N, Hirasawa Y. Nafamostat mesilate: a regional anticoagulant for hemodialysis in patients at high risk for bleeding. Nephron 1993;64:376-381.

98. Sahota S, Rodby R. Inpatient hemodialysis without anticoagulation in adults. Clin Kidney J 2014;7:552-556.

99. Guéry B, Alberti C, Servais A, et al. Hemodialysis without systemic anticoagulation: a prospective randomized trial to evaluate 3 strategies in patients at risk of bleeding. PLoS One 2014;9:e97187.

100. Lavaud S, Paris B, Maheut H, et al. Assessment of the heparin-binding AN69 ST hemodialysis membrane: II. Clinical studies without heparin administration. ASAIO J 2005;51:348-351.

101. Laville M, Dorval M, Fort Ros J, et al. Results of the HepZero study comparing heparin-grafted membrane and standard care show that heparin-grafted dialyzer is safe and easy to use for heparin-free dialysis. Kidney Int 2014;86:1260-1267.

102. Kreuzer M, Bonzel KE, Büscher R, Offner G, Ehrich JH, Pape L. Regional citrate anticoagulation is safe in intermittent highflux haemodialysis treatment of children and adolescents with an increased risk of bleeding. Nephrol Dial Transplant 2010;25:3337-3342.

103. Swartz RD, Flamenbaum W, Dubrow A, Hall JC, Crow JW, Cato A. Epoprostenol (PGI2, prostacyclin) during high-risk hemodialysis: preventing further bleeding complications. J Clin Pharmacol 1988;28:818-825.

104. Kalantar-Zadeh K, Regidor DL, Kovesdy CP, et al. Fluid retention is associated with cardiovascular mortality in patients undergoing long-term hemodialysis. Circulation 2009;119:671-679.

105. Stegmayr BG, Brannstrom M, Bucht S, et al. Minimized weight gain between hemodialysis contributes to a reduced risk of death. Int J Artif Organs 2006;29:675-680.

106. Foley RN, Herzog CA, Collins AJ; United States Renal Data System. Blood pressure and long-term mortality in United States hemodialysis patients: USRDS Waves 3 and 4 Study. Kidney Int 2002;62:1784-1790.

107. Saran R, Bragg-Gresham JL, Rayner HC, et al. Nonadherence in hemodialysis: associations with mortality, hospitalization, and practice patterns in the DOPPS. Kidney Int 2003;64:254-262.

108. Hecking M, Moissl U, Genser B, et al. Greater fluid overload and lower interdialytic weight gain are independently associated with mortality in a large international hemodialysis population. Nephrol Dial Transplant 2018;33:1832-1842.

109. Kurita N, Hayashino Y, Yamazaki S, et al. Revisiting interdialytic weight gain and mortality association with serum albumin interactions: the Japanese Dialysis Outcomes and Practice Pattern Study. J Ren Nutr 2017;27:421-429.

110. Toida T, Iwakiri T, Sato Y, Komatsu H, Kitamura K, Fujimoto S. Relationship between hemoglobin levels corrected by interdialytic weight gain and mortality in Japanese hemodialysis patients: Miyazaki Dialysis Cohort Study. PLoS One 2017;12:e0169117.

111. Lee MJ, Doh FM, Kim CH, et al. Interdialytic weight gain and cardiovascular outcome in incident hemodialysis patients. Am J Nephrol 2014;39:427-435.

112. Stefánsson BV, Brunelli SM, Cabrera C, et al. Intradialytic hypotension and risk of cardiovascular disease. Clin J Am Soc Nephrol 2014;9:2124-2132.

113. Wong MM, McCullough KP, Bieber BA, et al. Interdialytic weight gain: trends, predictors, and associated outcomes in the International Dialysis Outcomes and Practice Patterns Study (DOPPS). Am J Kidney Dis 2017;69:367-379.

114. Dantas LG, de Seixas Rocha M, Junior JA, Paschoalin EL, Paschoalin SR, Sampaio Cruz CM. Non-adherence to haemodialysis, interdialytic weight gain and cardiovascular mortality: a cohort study. BMC Nephrol 2019;20:402.

115. Leggat JE Jr, Orzol SM, Hulbert-Shearon TE, et al. Noncompliance in hemodialysis: predictors and survival analysis. Am J Kidney Dis 1998;32:139-145.

116. Watanabe Y, Yamagata K, Nishi S, et al. Japanese Society for Dialysis Therapy clinical guideline for "hemodialysis initiation for maintenance hemodialysis". Ther Apher Dial 2015;19 Suppl 
1:93-107.

117. Flythe JE, Kimmel SE, Brunelli SM. Rapid fluid removal during dialysis is associated with cardiovascular morbidity and mortality. Kidney Int 2011;79:250-257.

118. Saran R, Bragg-Gresham JL, Levin NW, et al. Longer treatment time and slower ultrafiltration in hemodialysis: associations with reduced mortality in the DOPPS. Kidney Int 2006;69:1222-1228.

119. Hecking M, Karaboyas A, Antlanger M, et al. Significance of interdialytic weight gain versus chronic volume overload: consensus opinion. Am J Nephrol 2013;38:78-90.

120. Dunlop JL, Vandal AC, de Zoysa JR, et al. Rationale and design of the Sodium Lowering In Dialysate (SoLID) trial: a randomised controlled trial of low versus standard dialysate sodium concentration during hemodialysis for regression of left ventricular mass. BMC Nephrol 2013;14:149.

121. Charra B, Calemard E, Ruffet M, et al. Survival as an index of adequacy of dialysis. Kidney Int 1992;41:1286-1291.

122. London GM, Pannier B, Guerin AP, et al. Alterations of left ventricular hypertrophy in and survival of patients receiving hemodialysis: follow-up of an interventional study. J Am Soc Nephrol 2001;12:2759-2767.

123. Mominadam S, Ozkahya M, Kayikcioglu M, et al. Interdialytic blood pressure obtained by ambulatory blood pressure measurement and left ventricular structure in hypertensive hemodialysis patients. Hemodial Int 2008;12:322-327.

124. FHN Trial Group, Chertow GM, Levin NW, et al. In-center hemodialysis six times per week versus three times per week. $N$ Engl J Med 2010;363:2287-2300.

125. Culleton BF, Walsh M, Klarenbach SW, et al. Effect of frequent nocturnal hemodialysis vs conventional hemodialysis on left ventricular mass and quality of life: a randomized controlled trial. JAMA 2007;298:1291-1299.

126. Katzarski KS, Charra B, Luik AJ, et al. Fluid state and blood pressure control in patients treated with long and short haemodialysis. Nephrol Dial Transplant 1999;14:369-375.

127. Wald R, Yan AT, Perl J, et al. Regression of left ventricular mass following conversion from conventional hemodialysis to thrice weekly in-centre nocturnal hemodialysis. BMC Nephrol 2012;13:3.

128. Chan CT, Floras JS, Miller JA, Richardson RM, Pierratos A. Regression of left ventricular hypertrophy after conversion to nocturnal hemodialysis. Kidney Int 2002;61:2235-2239.

129. Marshall MR, Dunlop JL. Are dialysate sodium levels too high? Semin Dial 2012;25:277-283.

130. Kim SM, Kim JG, Shin JH, et al. The effects of low sodium dialy- sate in hemodialysis patients. Korean J Nephrol 2011;30:53-60.

131. Dunlop JL, Vandal AC, Marshall MR. Low dialysate sodium levels for chronic haemodialysis. Cochrane Database Syst Rev 2019;1:CD011204.

132. Beduschi GC, Telini LS, Caramori JC, Martin LC, Barretti P. Effect of dialysate sodium reduction on body water volume, blood pressure, and inflammatory markers in hemodialysis patients: a prospective randomized controlled study. Ren Fail 2013;35:742-747.

133. Boquin E, Parnell S, Grondin G, et al. Crossover study of the effects of different dialysate sodium concentrations in large surface area, short-term dialysis. Proc Clin Dial Transplant Forum 1977;7:48-52.

134. Liu J, Sun F, Ma LJ, Shen Y, Mei X, Zhou YL. Increasing dialysis sodium removal on arterial stiffness and left ventricular hypertrophy in hemodialysis patients. J Ren Nutr 2016;26:38-44.

135. Akyol A, Akdag S, Asker M, et al. Effects of lowered dialysate sodium on left ventricle function and brain natriuretic peptide in maintenance of hemodialysis patients. Hum Exp Toxicol 2017;36:128-134.

136. Arramreddy R, Sun SJ, Munoz Mendoza J, Chertow GM, Schiller B. Individualized reduction in dialysate sodium in conventional in-center hemodialysis. Hemodial Int 2012;16:473-480.

137. Kooman JP, Hendriks EJ, van Den Sande FM, Leumissen KM. Dialysate sodium concentration and blood pressure control in haemodialysis patients. Nephrol Dial Transplant 2000;15:554.

138. Sayarlioglu H, Erkoc R, Tuncer M, et al. Effects of low sodium dialysate in chronic hemodialysis patients: an echocardiographic study. Ren Fail 2007;29:143-146.

139. Zhou YL, Liu J, Ma LJ, et al. Effects of increasing diffusive sodium removal on blood pressure control in hemodialysis patients with optimal dry weight. Blood Purif2013;35:209-215.

140. Amro A, Waldum B, Dammen T, Miaskowski C, Os I. Symptom clusters in patients on dialysis and their association with quality-of-life outcomes. J Ren Care 2014;40:23-33.

141. Caplin B, Kumar S, Davenport A. Patients' perspective of haemodialysis-associated symptoms. Nephrol Dial Transplant 2011;26:2656-2663.

142. Heerspink HJ, Ninomiya T, Zoungas S, et al. Effect of lowering blood pressure on cardiovascular events and mortality in patients on dialysis: a systematic review and meta-analysis of randomised controlled trials. Lancet 2009;373:1009- 1015.

143. Hannedouche T, Roth H, Krummel T, et al. Multiphasic effects of blood pressure on survival in hemodialysis patients. Kidney Int 2016;90:674-684. 
144. Jhee JH, Park J, Kim H, et al. The optimal blood pressure target in different dialysis populations. Sci Rep 2018;8:14123.

145. Van Buren PN, Kim C, Toto R, Inrig JK. Intradialytic hypertension and the association with interdialytic ambulatory blood pressure. Clin J Am Soc Nephrol 2011;6:1684-1691.

146. Assimon MM, Brookhart MA, Fine JP, Heiss G, Layton JB, Flythe JE. A comparative study of carvedilol versus metoprolol initiation and 1-year mortality among individuals receiving maintenance hemodialysis. Am J Kidney Dis 2018;72:337-348.

147. Agarwal R, Alborzi P, Satyan S, Light RP. Dry-weight reduction in hypertensive hemodialysis patients (DRIP): a randomized, controlled trial. Hypertension 2009;53:500-507.

148. Zhang H, Preciado P, Wang Y, et al. Association of all-cause mortality with predialysis systolic blood pressure and its peridialytic change in chronic hemodialysis patients. Nephrol Dial Transplant 2020;35:1602-1608.

149. Alborzi P, Patel N, Agarwal R. Home blood pressures are of greater prognostic value than hemodialysis unit recordings. Clin J Am Soc Nephrol 2007;2:1228-1234.

150. Agarwal R, Peixoto AJ, Santos SF, Zoccali C. Pre- and postdialysis blood pressures are imprecise estimates of interdialytic ambulatory blood pressure. Clin J Am Soc Nephrol 2006;1:389-398.

151. Tsujimoto Y, Tsujimoto H, Nakata Y, et al. Dialysate temperature reduction for intradialytic hypotension for people with chronic kidney disease requiring haemodialysis. Cochrane Database Syst Rev 2019;7:CD012598.

152. Selby NM, Burton JO, Chesterton LJ, McIntyre CW. Dialysis-induced regional left ventricular dysfunction is ameliorated by cooling the dialysate. Clin J Am Soc Nephrol 2006;1:1216-1225.

153. Chesterton LJ, Selby NM, Burton JO, McIntyre CW. Cool dialysate reduces asymptomatic intradialytic hypotension and increases baroreflex variability. Hemodial Int 2009;13:189-196.

154. Fine A, Penner B. The protective effect of cool dialysate is dependent on patients' predialysis temperature. Am J Kidney Dis 1996;28:262-265.

155. Jost CM, Agarwal R, Khair-el-Din T, Grayburn PA, Victor RG, Henrich WL. Effects of cooler temperature dialysate on hemodynamic stability in "problem" dialysis patients. Kidney Int 1993;44:606-612.

156. Ayoub A, Finlayson M. Effect of cool temperature dialysate on the quality and patients' perception of haemodialysis. Nephrol Dial Transplant 2004;19:190-194.

157. Maggiore Q, Pizzarelli F, Santoro A, et al. The effects of control of thermal balance on vascular stability in hemodialysis patients: results of the European randomized clinical trial. Am J
Kidney Dis 2002;40:280-290.

158. Jefferies HJ, Burton JO, McIntyre CW. Individualised dialysate temperature improves intradialytic haemodynamics and abrogates haemodialysis-induced myocardial stunning, without compromising tolerability. Blood Purif2011;32:63-68.

159. Cruz DN, Mahnensmith RL, Brickel HM, Perazella MA. Midodrine and cool dialysate are effective therapies for symptomatic intradialytic hypotension. Am J Kidney Dis 1999;33:920926.

160. Azar AT. Effect of dialysate temperature on hemodynamic stability among hemodialysis patients. Saudi J Kidney Dis Transpl 2009;20:596-603.

161. Hegbrant J, Thysell H, Mårtensson L, Nielsen AL, Lindberg BF. Delayed decrease in plasma levels of atrial natriuretic peptide during cold hemodialysis. Nephron 1994;68:427-432.

162. Selby NM, McIntyre CW. A systematic review of the clinical effects of reducing dialysate fluid temperature. Nephrol Dial Transplant 2006;21:1883-1898.

163. Mustafa RA, Bdair F, Akl EA, et al. Effect of lowering the dialysate temperature in chronic hemodialysis: a systematic review and meta-analysis. Clin J Am Soc Nephrol 2016;11:442-457.

164. Owen WF Jr, Lew NL, Liu Y, Lowrie EG, Lazarus JM. The urea reduction ratio and serum albumin concentration as predictors of mortality in patients undergoing hemodialysis. $N$ Engl J Med 1993;329:1001-1006.

165. Hakim RM, Breyer J, Ismail N, Schulman G. Effects of dose of dialysis on morbidity and mortality. Am J Kidney Dis 1994;23:661669.

166. Parker TF 3rd, Husni L, Huang W, Lew N, Lowrie EG. Survival of hemodialysis patients in the United States is improved with a greater quantity of dialysis. Am J Kidney Dis 1994;23:670-680.

167. Collins AJ, Ma JZ, Umen A, Keshaviah P. Urea index and other predictors of hemodialysis patient survival. Am J Kidney Dis 1994;23:272-282.

168. Thomas A, Silver SA, Perl J, et al. The frequency of routine blood sampling and patient outcomes among maintenance hemodialysis recipients. Am J Kidney Dis 2020;75:471-479.

169. Hemodialysis Adequacy 2006 Work Group. Clinical practice guidelines for hemodialysis adequacy, update 2006. Am J Kidney Dis 2006;48 Suppl 1:S2-S90.

170. Tattersall J, Martin-Malo A, Pedrini L, et al. EBPG guideline on dialysis strategies. Nephrol Dial Transplant 2007;22 Suppl 2:ii5ii21.

171. Drüeke TB, Parfrey PS. Summary of the KDIGO guideline on anemia and comment: reading between the (guide)line(s). 
Kidney Int 2012;82:952-960.

172. Kidney Disease: Improving Global Outcomes (KDIGO) CKDMBD Work Grou. KDIGO clinical practice guideline for the diagnosis, evaluation, prevention, and treatment of chronic kidney disease-mineral and bone disorder (CKD-MBD). Kidney Int Suppl 2009;113:S1-S130.

173. Kidney Disease: Improving Global Outcomes (KDIGO) CKDMBD Update Work Group. KDIGO 2017 clinical practice guideline update for the diagnosis, evaluation, prevention, and treatment of chronic kidney disease-mineral and bone disorder (CKD-MBD). Kidney Int Suppl (2011) 2017;7:1-59.

174. Kidney Disease: Improving Global Outcomes (KDIGO) Hepatitis C Work Group. KDIGO 2018 clinical practice guideline for the prevention, diagnosis, evaluation, and treatment of hepatitis C in chronic kidney disease. Kidney Int Suppl (2011) 2018;8:91-165.

175. Jardine M, Commons RJ, de Zoysa JR, et al. Kidney Health Australia: caring for Australasians with renal impairment guideline recommendations for infection control for haemodialysis units. Nephrology (Carlton) 2019;24:951-957.

176. Garthwaite E, Reddy V, Douthwaite S, Lines S, Tyerman K, Eccles J. Clinical practice guideline management of blood borne viruses within the haemodialysis unit. BMC Nephrol 2019;20:388.

177. Foote C, Kotwal S, Gallagher M, Cass A, Brown M, Jardine M. Survival outcomes of supportive care versus dialysis therapies for elderly patients with end-stage kidney disease: a systematic review and meta-analysis. Nephrology (Carlton) 2016;21:241-253.

178. Wongrakpanich S, Susantitaphong P, Isaranuwatchai S, Chenbhanich J, Eiam-Ong S, Jaber BL. Dialysis therapy and conservative management of advanced chronic kidney disease in the elderly: a systematic review. Nephron 2017;137:178-189.

179. Smith C, Da Silva-Gane M, Chandna S, Warwicker P, Greenwood R, Farrington K. Choosing not to dialyse: evaluation of planned non-dialytic management in a cohort of patients with end-stage renal failure. Nephron Clin Pract 2003;95:c40-c46.

180. Joly D, Anglicheau D, Alberti C, et al. Octogenarians reaching end-stage renal disease: cohort study of decision-making and clinical outcomes. J Am Soc Nephrol 2003;14:1012-1021.

181. Murtagh FE, Marsh JE, Donohoe P, Ekbal NJ, Sheerin NS, Harris FE. Dialysis or not?: a comparative survival study of patients over 75 years with chronic kidney disease stage 5. Nephrol Dial Transplant 2007;22:1955-1962.

182. Carson RC, Juszczak M, Davenport A, Burns A. Is maximum conservative management an equivalent treatment option to dialysis for elderly patients with significant comorbid disease? Clin J Am Soc Nephrol 2009;4:1611-1619.

183. Brown MA, Collett GK, Josland EA, Foote C, Li Q, Brennan FP. CKD in elderly patients managed without dialysis: survival, symptoms, and quality of life. Clin J Am Soc Nephrol 2015;10: 260-268.

184. Raman M, Middleton RJ, Kalra PA, Green D. Outcomes in dialysis versus conservative care for older patients: a prospective cohort analysis of stage 5 chronic kidney disease. PLoS One 2018;13:e0206469.

185. van Loon IN, Goto NA, Boereboom FT, Verhaar MC, Bots ML, Hamaker ME. Quality of life after the initiation of dialysis or maximal conservative management in elderly patients: a longitudinal analysis of the Geriatric assessment in OLder patients starting Dialysis (GOLD) study. BMC Nephrol 2019;20:108.

186. Verberne WR, Geers AB, Jellema WT, Vincent HH, van Delden JJ, Bos WJ. Comparative survival among older adults with advanced kidney disease managed conservatively versus with dialysis. Clin J Am Soc Nephrol 2016;11:633-640.

187. Reindl-Schwaighofer R, Kainz A, Kammer M, Dumfarth A, Oberbauer R. Survival analysis of conservative vs. dialysis treatment of elderly patients with CKD stage 5. PLoS One 2017;12: $\mathrm{e} 0181345$.

188. Tam-Tham H, Quinn RR, Weaver RG, et al. Survival among older adults with kidney failure is better in the first three years with chronic dialysis treatment than not. Kidney Int 2018;94:582-588.

189. Pyart R, Aggett J, Goodland A, et al. Exploring the choices and outcomes of older patients with advanced kidney disease. PLoS One 2020;15:e234309.

190. Tam-Tham H, Ravani P, Zhang J, et al. Association of initiation of dialysis with hospital length of stay and intensity of care in older adults with kidney failure. JAMA Netw Open 2020;3:e200222.

191. Han SS, Park JY, Kang S, et al. Dialysis modality and mortality in the elderly: a meta-analysis. Clin J Am Soc Nephrol 2015;10:983993.

192. Kaur A, Davenport A. Hemodialysis for infants, children, and adolescents. Hemodial Int 2014;18:573-582.

193. Chand DH, Swartz S, Tuchman S, Valentini RP, Somers MJ. Dialysis in children and adolescents: the pediatric nephrology perspective. Am J Kidney Dis 2017;69:278-286.

194. Salerno AE, Weinstein A, Hanevold C. American Society of Pediatric Nephrology position paper: standard resources required for a pediatric nephrology practice. J Pediatr 2016;174:254-259.

195. Jones L, Aldridge M. organization and management of a pediatric dialysis program. In: Warady B, Schaefer F, Alexander S, 
editors. Pediatric dialysis. 2nd ed. New York: Springer; 2012.

196. British Renal Society. The Renal Team: a multi-professional renal workforce plan for adults and children with renal disease. Recommendations of the National Renal Workforce Planning Group. Lichfield (UK): British Renal Society; 2002.

197. UniBritish Columbia Nurses' Union (BCNU). BCNU Position
Statement on mandated nurse-patient ratios. Burnaby (BC): BCNU; 2011.

198. Thomas-Hawkins C, Flynn L, Clarke SP. Relationships between registered nurse staffing, processes of nursing care, and nurse-reported patient outcomes in chronic hemodialysis units. Nephrol Nurs J 2008;35:123-130,145 